\title{
Validation of a new elastoplastic constitutive model dedicated to the cyclic behaviour of brittle rock materials
}

\author{
B. Cerfontaine - R. Charlier - F. Collin - M. \\ Taiebat
}

Received: date / Accepted: date

\begin{abstract}
Old mines or caverns may be used as reservoirs for fuel/gas storage or in the context of large scale energy storage. In the first case, oil or gas is stored on annual basis. In the second case pressure due to water or compressed air varies on a daily basis or even faster. In both cases a cyclic loading on the cavern's/mine's walls must be considered for the design. The complexity of rockwork geometries or coupling with water flow requires finite element modelling and then a suitable constitutive law for the rock behaviour modelling.

This paper presents and validates the formulation of a new constitutive law able to represent the inherently cyclic behaviour of rocks at low confinement. The main features of the behaviour evidenced by experiments in the literature depict a progressive degradation and strain of the material with the number of cycles. A constitutive law based on a boundary surface concept is developed. It represents the brittle failure of the material as well as its progressive degradation. Kinematic hardening of the yield surface allows the modelling of cycles. Isotropic softening on the cohesion variable leads to the progressive degradation of the rock strength. A limit surface is introduced and has a lower opening than the bounding surface. This surface describes the peak strength of the material and allows the modelling of a brittle behaviour. In addition a fatigue limit is introduced such that no cohesion degradation occurs if the stress state lies inside this surface.

The model is validated against three different rock materials and types of experi-
\end{abstract}

B. Cerfontaine, F. Collin, R. Charlier

Urban and Environmental Engineering

University of Liege

Allee de la Decouverte, 9

4000, Liege, Belgium

E-mail: f.collin@ulg.ac.be

M. Taiebat

Department of Civil Engineering

University of British Columbia

Vancouver, Canada

E-mail: mtaiebat@civil.ubc.ca 
ments. Parameters of the constitutive laws are calibrated against uniaxial tests on Lorano marble, triaxial test on a sandstone and damage controlled test on Lac du Bonnet granite. The model is shown to reproduce correctly experimental results, especially the evolution of strain with number of cycles.

Keywords Fatigue $\cdot$ Constitutive modelling $\cdot$ Bounding surface model Cyclic loading $\cdot$ Rock Mechanics 


\section{List of symbols}

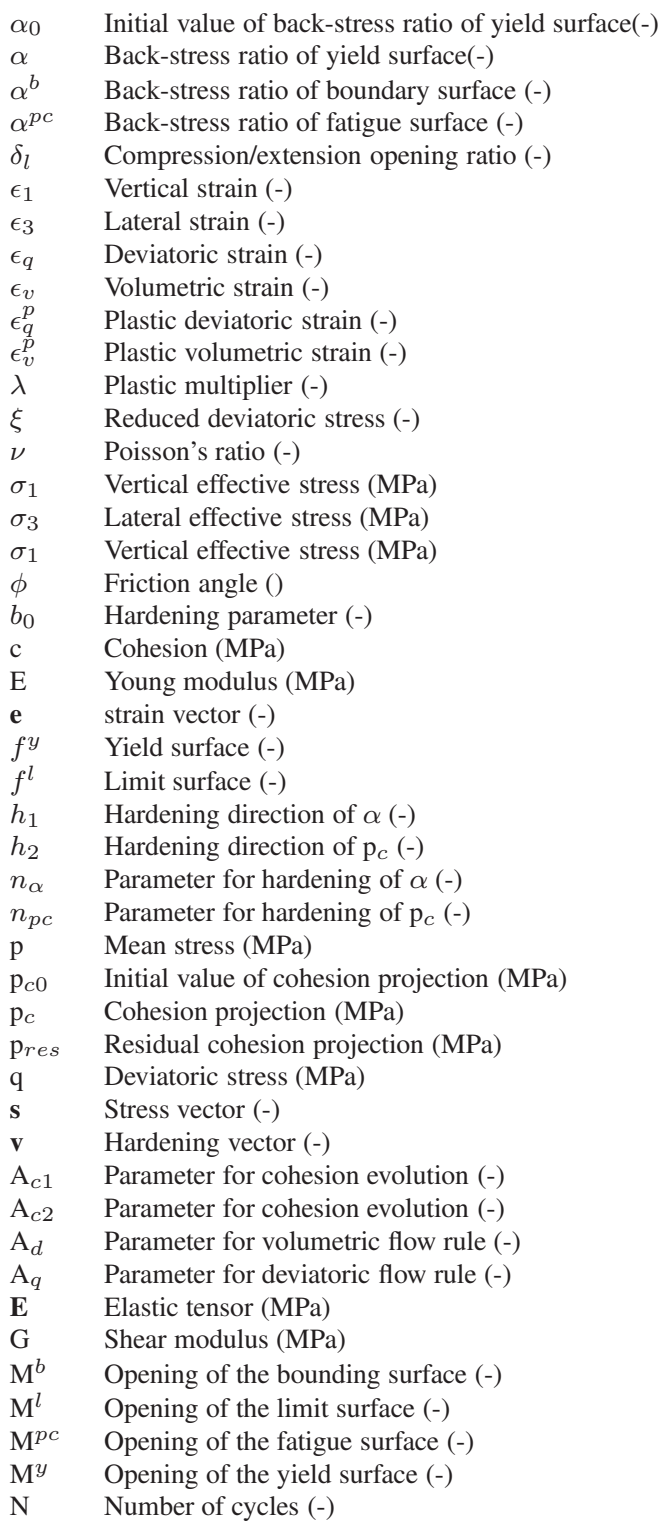

\section{Introduction}

Over the last decade, the part of renewable energy has considerably grown in the energy mix. However solar and wind energy particularly suffer from a crucial draw- 
back, their intermittent nature. The period of maximum production does not necessarily coincide with the period of maximum consumption (Førsund, 2015). Two systems allow a very large energy storage deliverability ( $>100 \mathrm{MW}$ with a single unit): pumped hydroelectric storage (PHS) and compressed air energy storage (CAES) (Chen et al., 2009).

PHS stores energy as gravitational potential energy. Water is pumped from a lower reservoir into a higher reservoir when electric power is available at a low cost (off-peak of consumption) (Steffen, 2012). During the peak of energy consumption, turbines produce energy at a higher cost, ensuring the economic viability of the system. This system is already widely used all over the world with more than 200 sites and 100GW of installed power in 2005. Reservoirs used may be created artificially for that purpose. However abandoned mines or open pits may be used as investigated by Pujades et al. (2016).

CAES working is a bit more complex and works on the basis of conventional gas turbine (Chen et al., 2009). During low demand air is stored and compressed to 4-8 $\mathrm{MPa}$. To recover stored energy, air is heated and expanded through a high pressure turbine first. It is then mixed with fuel and combusted with the exhaust expanded through a low pressure turbine. This system is much less widespread. The first plant was built in 1978 in Huntorf, Germany, in an abandoned salt mine (Raju \& Kumar Khaitan, 2012; Mahmoudi et al., 2016). A second unit is in operation in Alabama since 1991.

The opportunity to build such systems is strongly dependent on the geography (height difference between reservoirs), space available to build reservoir, environmental concerns and capital costs (Chen et al., 2009). Reusing abandoned mines as reservoir solves some of these issues. However ensuring the overall stability of the mine galleries and walls becomes a challenge. While storage of natural gas has an annual period, PSH and CAES are operated in daily cycles or faster. Therefore variations of air or water pressures induce a cyclic loading of rock walls.

Experimental investigations of the fatigue behaviour of rock material are scarce and complex to carry out (Attewell \& Farmer, 1973; Martin \& Chandler, 1994; Gatelier et al., 2002; Royer-Carfagni \& Salvatore, 2000; Erarslan \& Williams, 2012; Liu \& He, 2012; Wang et al., 2013; Liu et al., 2014; Ghamgosar \& Erarslan, 2015). However it clearly appears that failure of the material may be reached upon cyclic loading for an amplitude significantly lower than the monotonic resistance. This result is of paramount importance for design. Given the lifespan of the rock structure, the maximum number of cycles or the maximum amplitude that could be sustained must be assessed.

Models able to reproduce evolution of rock strength with cyclic loading are very limited (Li et al., 2003; Xiao et al., 2009, 2010; Bastian et al., 2014; Liu et al., 2014). They mostly consist in predicting strength or strain evolution of triaxial or uniaxial laboratory tests for a given material with respect to the number of cycles. General constitutive laws (stress-strain relation) able to reproduce this cyclic behaviour numerically in a finite element code have deserved even less attention. A Ramberg-Osgood based model is proposed by Hueckel (1991) using discretised kinematic hardening concept while a bounding surface approach is developed by Wang et al. (2015) for granite. Two models dedicated to more ductile salt rocks are developed respectively 
base on elasto-viscoplasticity (Khaledi et al., 2016a,b) or a micro-macro viscous approach (Pouya et al., 2016).

On the contrary, much more work is devoted to the cyclic behaviour of plain concrete material or concrete with fibres, which have a behaviour similar to natural rocks. Damage mechanics is the mostly used framework (Peng \& Meyer, 2000; Alliche, 2004; Wu et al., 2006; Mazars et al., 2015; Breccolotti et al., 2015). Another model couples damage evolution and bounding surface model (Suaris et al., 1990). Separate compliance matrices are introduced in tension and compression since crack growths mechanisms are different. It was successfully applied to the modelling of low-cycle experiments.

The objective of this paper is to develop, formulate and validate a constitutive law able to reproduce the cyclic behaviour of brittle rock materials. The paper aims at developing a physically based model with a reasonable amount of parameters that must be calibrated. It is validated against results published in the literature for three different materials.

Contrary to rock materials, different models exist for the cyclic behaviour of sands such as the Prevost model (Prevost, 1985; Cerfontaine et al., 2015), generalised plasticity (Mira et al., 2009) or subloading surface (Hashiguchi, 2009). The formulation proposed hereinafter is based on the bounding surface plasticity (Dafalias, 1986), the pioneering work on its application in form a two surface plasticity model for sands (Manzari \& Dafalias, 1997) which was later extended further (Dafalias \& Manzari, 2004; Dafalias et al., 2004; Taiebat \& Dafalias, 2008; Li \& Dafalias, 2012; Dafalias $\&$ Taiebat, 2016) and adopted the title of SANISAND, an acronym term for Simple ANIsotropic SAND. This framework is mainly chosen for its ability to reproduce accumulation of plastic strain upon constant amplitude cycles, for its physically based concept and relative simplicity. In addition, review of results published in the literature highlights that damaging of elastic properties is not always observed or may be neglected during fatigue experiments. Therefore the accumulation of plastic strain is of greater importance.

The model is composed of a yield surface subject to kinematic hardening, allowing accumulation of plastic strain due to cyclic loading. A limit surface represents the failure locus of the material. Cohesion is the main internal variable and is degraded cycle after cycle, finally leading to failure. A bounding surface is introduced to compute the stiffness of the material. Its slope is larger than or equal to the limit surface in order to reproduce both ductile (tangent modulus tends to zero at failure) or brittle failure (limited decrease of tangent modulus with respect to elastic stiffness).

First section gathers main features of the cyclic behaviour of rock materials observed in laboratory. The triaxial formulation of the model is then derived and constitutive equations are detailed. Finally physical parameters are calibrated with respect to three different types of rocks cyclically loaded in simple compression or triaxial conditions.

\section{Experimental review}

The objective of this section is to highlight main features of monotonic and cyclic behaviours of brittle rock materials. These mechanisms must be correctly reprodu- 
ced by any constitutive law. Confining pressures investigated in the following remain limited (with respect to their simple compression strength) since the application of the model targets the modelling of mine galleries or open pits. In these cases, rock material around galleries or close to the pit's wall is close to simple compression conditions.

Brittle rock materials, by definition, exhibit only small plastic strain before failure, despite ductility may increase with confining pressure (Liu \& He, 2012). The strength increases with confining pressure, which is a fundamental ingredient of any constitutive law. Many other features could be relevant such as: material (Attewell \& Farmer, 1973 ) anisotropy, load-induced anisotropy (Benz \& Schwab, 2008) or creep behaviour (Brantut et al., 2013). However they are not considered in the following.

A constitutive law should be consistent with the failure mode of the rock sample it represents. Failure of brittle rock is mainly driven by the generation of microcracks that finally coalesce within a single macrocrack. Relations between macrocrack behaviour (vertical and volumetric deformation) and microcracking were described in pioneering work of (Bieniawski, 1967a,b). However as described in the following, cyclic mechanisms are slightly different.

Cyclic behaviour of rock depends on the material investigated but also on the type of cyclic loading applied. However it results in a weakening of the tested sample and finally a failure occurs for a maximum stress lower than the monotonic resistance. The typical behaviour of a Lorano marble is presented in Fig1. Cyclic loading generates accumulation of plastic strain within the material cycle after cycle. The effect on lateral strain $\epsilon_{3}$ is more marked than on axial strain $\epsilon_{1}$ and results from dilatancy and microcracks. The hysteretic behaviour of the cycles tends to increase progressively. The first cycle is very different from the following ones. It is more open and generates more residual strain. This is generally observed in cyclic results but not totally explained. It is mainly due to hardening of the material but also to experimental setup (non-parallel faces of the sample, sliding...).

Fig1 also highlights the inherent heterogeneity related to rock materials. While two simple compression tests are carried out on a Lorano marble, it is clear that the response corresponds to two samples having different strength parameters. If the first compression and monotonic results are compared, it appears that the stiffness and strength are different. For an identical deviatoric stress q, more plastic strain are generated in monotonic results. This may be due to different rock blocs, weathering of the material, loading rate or simply damages due to sampling.

Constant amplitude cyclic loading consists in imposing variations of stress between a minimum and a maximum value (lower than estimated monotonic peak strength). Such a loading is reported to generate plastic strain cycle after cycle as described in Fig1. However this accumulation rate is non-linear and increases when sample approaches failure. Plastic strain accumulated is often represented with respect to the number of cycles applied as depicted in Fig2. In this figure axial residual strain for a sandstone is compared at six confining pressures. Three phases are often identified (Liu \& He, 2012): a decelerating accumulation of plastic strain, a stationary phase and finally an accelerating phase.

Residual strain at the end of the cyclic test increases with confining pressure. However there is not clear tendency related to the number of cycles to failure. Some 
studies (Haimson \& Kim, 1971; Burdine, 1963; Erarslan et al., 2014) report that the number of cycles to failure depends on the ratio of the maximum cyclic amplitude to the monotonic resistance $\mathrm{q}_{\max } / \mathrm{q}_{\text {peak }}$. Therefore a rigorous comparison of behaviour at different confinements would require to impose the same ratio to all samples, since $\mathrm{q}_{\text {peak }}$ increases with confinement. However most of the time the peak strength is unknown a priori because rock material is inherently heterogeneous. Therefore it is very difficult to compare results.

Fig3 presents an indirect tensile cyclic test on a Brisbane tuff. The cyclic amplitude is constant but the mean stress increases linearly (Erarslan \& Williams, 2012). Cyclic maximum stress is significantly lower than the monotonic resistance, revealing that cyclic load has a progressive weakening effect, even for moderate amplitudes. This is also marked in Fig1, despite monotonic and cyclic results are not easy to compare (first cycle and monotonic test have a different behaviour).

Failure modes are shown to be quite different in both cases. The monotonic samples present a straight crack while a larger and branching fractured zone is observed upon cyclic loading (Ghamgosar \& Erarslan, 2015). In addition these samples are surrounded by debris and crushed rock material. This suggests that much more microcracks are generated (Erarslan \& Williams, 2012). It is then concluded that fatigue is generated by a progressive debonding, loosening and decohesion of rock matrix.

For a given confining pressure and loading type (indirect tensile test, simple compression or triaxial), it is shown that a threshold exists on the cyclic amplitude below which there is no failure of the material even upon a large number of cycles (Burdine, 1963; Haimson \& Kim, 1971; Prost, 1988; Erarslan \& Williams, 2012). Fig4 presents the number of cycles as a function of the amplitude applied for indirect tensile test on Brisbane tuff (Erarslan \& Williams, 2012). When the amplitude is below $70 \%$ of the monotonic resistance, no failure was observed even after more than 500000 cycles. This threshold is defined as the fatigue resistance of the material.

A sketch of a damage controlled test is represented in Fig5. In such a test, the maximum axial strain is increased cycle after cycle before unloading to a minimum stress $\mathrm{q}_{\min }$. Therefore pre-peak and post-peak behaviour are both investigated. Subsequently the stress amplitude increases before peak and decreases after.

An example proposed by Martin \& Chandler (1994) consists of a triaxial cyclic tests where the maximum cyclic stress varies, as depicted in Fig6. Up to 75\% of the peak strength, it is incremented of $40 \mathrm{MPa}$ before reversal to unloading phase. After this threshold, the load cycles are performed by increments of circumferential strain equal to $0.063 \mathrm{~mm}$, before reversal.

Similarly to constant amplitude loading, cycles are prone to open progressively and especially in the post-peak zone. Plastic strain are accumulated cycle after cycle. However it is shown by Martin \& Chandler (1994) that elastic properties are prone to damaging especially in the post-peak domain and at low confinement. In addition it is shown that the monotonic results act almost as a failure locus in the $q-\epsilon_{1}$ plane for the cyclic results at identical confinement.

A conclusion of the study presented by Martin \& Chandler (1994); Martin (1997) is that cohesion is progressively decreased cycle after cycle as a consequence of sample damaging. This is correlated with the opening and propagation of microcracks. 


\section{Triaxial formulation of a constitutive law}

The objective of this section is to formulate a constitutive law in triaxial notations. Indeed in the following only simple compression and triaxial tests are modelled. In addition these notations simplify the formulation of the model and better highlight how it works.

This work is derived from the bounding surface plasticity concept (Dafalias, 1986 ) and its application in the framework of SANISAND models (Manzari \& Dafalias, 1997; Dafalias \& Manzari, 2004; Dafalias et al., 2004; Taiebat \& Dafalias, 2008; Li \& Dafalias, 2012; Dafalias \& Taiebat, 2016). This choice is justified by the capability of these models to reproduce accumulation of plastic strain for constant cycle amplitude. In this work, creep and dynamic effects are not taken into account.

\subsection{Triaxial notations}

In triaxial conditions, only the diagonal components of the strain $\epsilon$ and effective stress $\sigma$ tensors are different from zero. Two stress invariants describe the stress state of the material

$$
\begin{aligned}
& \mathrm{p}=\left(\sigma_{1}+2 \sigma_{3}\right) / 3, \\
& \mathrm{q}=\sigma_{1}-\sigma_{3},
\end{aligned}
$$

where $\sigma_{1}$ and $\sigma_{3}$ are respectively the vertical and lateral effective stresses applied to the sample. The stresses are gathered into the vector $\mathbf{s}^{T}=\left[\begin{array}{ll}\mathrm{q}, & \mathrm{p}\end{array}\right]$ where ${ }^{T}$ is the transpose operator. A reduced deviatoric stress $\xi$ is defined according to

$$
\xi=\frac{\mathrm{q}}{\mathrm{p}+\mathrm{p}_{c}}
$$

where $\mathrm{p}_{c}$ is further defined in Equation (6). Similarly strain invariants are defined according to

$$
\begin{aligned}
& \epsilon_{v}=\epsilon_{1}+2 \epsilon_{3}, \\
& \epsilon_{q}=\epsilon_{1}-\epsilon_{3},
\end{aligned}
$$

where $\epsilon_{1}$ and $\epsilon_{3}$ are the vertical and lateral strains. They are assembled into the vector $\mathbf{e}^{T}=\left[\epsilon_{q}, \epsilon_{v}\right]$.

\subsection{Surfaces}

The model is defined by different surfaces in the p-q plane. A yield surface $\mathrm{M}^{y}$ delineates the elastic range. The plastic modulus is proportional to the distance between the stress state and the bounding surface $\mathrm{M}^{b}$. Subsequently when the stress state approaches the bounding surface, this distance tends to zero, leading to a zero plastic modulus and a ductile behaviour. 
In this work, brittle material are investigated. Therefore upon monotonic loading, a peak strength must be encountered followed by softening, after a limited plastic strain. Therefore a new surface $\mathrm{M}^{l} \leq \mathrm{M}^{b}$ but homothetic to $\mathrm{M}^{b}$ in introduced. The stress state is not allowed to overcome $\mathrm{M}^{l}$, which is termed limit surface. It will be shown in the following that reaching this surface will be synonym of failure, namely reaching a peak resistance.

Fig7 summarises differences between original and modified concepts through a uniaxial compression, if critical state effect is neglected. If the slopes of limit and bounding surfaces are identical $\mathbf{M}^{b}=\mathbf{M}^{l}$, distance between the stress state and bounding surface comes very close to zero leading to a ductile behaviour. The stress state tends asymptotically to the bounding surface but never reaches it. On the other hand if those surfaces are distinct $\mathrm{M}^{b}>\mathrm{M}^{l}$, the stress state reaches the limit surface while the distance to the bounding surface is different from zero, namely the plastic modulus is non null. The behaviour is brittle.

All surface are represented in Fig8, only on the compression side ( $q>0$ ) for clarity. All surfaces are homothetic and share a common apex located on the p-axis at coordinate $-\mathrm{p}_{c}$ which is a function of the cohesion $c$ and the friction angle $\phi$

$$
\mathrm{p}_{c}=\frac{c}{\tan \phi}
$$

where $\phi$ is the friction angle.

The yield surface delineates the elastic domain and has an opening of $2 \mathrm{M}^{y}$. The opening of this surface is constant but the position of its axis evolves from its initial position $\alpha=0$, namely an axis centred on the $\mathrm{p}$ axis. The initial stress state must lie inside or on this surface. Its mathematical formulation reads

$$
f^{y} \equiv\left(q-\left(\mathrm{p}+\mathrm{p}_{c}\right) \alpha\right)^{2}-\left(\mathrm{p}+\mathrm{p}_{c}\right)^{2}\left(\mathbf{M}^{y}\right)^{2}
$$

where $\alpha$ is termed the back-stress ratio of the surface. This surface is subject to kinematic hardening inducing variations of $\alpha$ within the following limits

$$
\begin{array}{ll}
\alpha+\mathbf{M}^{y} \leq \mathbf{M}^{l} & \text { in compression, } \\
\alpha-\mathbf{M}^{y} \geq \mathbf{M}^{l} / \delta^{l} & \text { in extension, }
\end{array}
$$

where $\mathrm{M}^{l}$ is the slope of the limit surface and $\delta^{l}$ is the ratio between the compression and extension openings of the limit surface. The slope $\mathbf{M}^{l}$ is related to the friction angle through

$$
\mathbf{M}^{l}=\frac{6 \sin \phi}{3-\sin \phi}
$$

The yield surface is then a function of two internal variables: $\alpha$ and $\mathrm{p}_{c}$. The limit surface is the failure locus associated to the material, namely it describes the peak strength of the material. It is given by

$$
f^{l} \equiv \mathrm{q}^{2}-\left(\mathrm{p}+\mathrm{p}_{c}\right)^{2}\left(\mathrm{M}^{l}\right)^{2}
$$

and depends only on the internal variable $\mathrm{p}_{c}$. 
Experimental results evidence that cohesion loss is the main strength degradation mechanism of rock samples as reported in section 2. Therefore limit surface should be subject to softening (cohesion $\mathrm{p}_{c}$ decreases) during loading. In addition cyclic loading seems to have no effect beyond a given threshold, namely there is no strength reduction. Therefore we introduce a fatigue surface $\mathbf{M}^{p c}$, homothetic to the bounding surface Equation (11), which is a threshold below which no strength degradation occurs. If the stress path lies within this surface, there is no cohesion weakening. If the stress path lies outside this surface, cohesion is degraded.

\subsection{Flow rule}

Plastic strain are assumed to be proportional to the reduced deviatoric stress. In addition the flow rule is non-associated to take into account the volumetric dilatancy due to crack opening. The variations of the plastic components of strain are defined such that

$$
\dot{\mathbf{e}}^{p}=\left[\begin{array}{c}
\dot{\epsilon}_{q}^{p} \\
\dot{\epsilon}_{v}^{p}
\end{array}\right]=\dot{\lambda}\left[\begin{array}{c}
A_{q} \xi \\
A_{d} \xi
\end{array}\right]=\dot{\lambda} \mathbf{G}
$$

where $\dot{\lambda}$ is the variation of the plastic multiplier, $A_{q}$ is a material parameter and $A_{d}$ is a parameter of dilatancy.

\subsection{Hardening of internal variables}

There are two main internal variables in this model: the back-stress ratio $\alpha$ and the cohesion $\mathrm{p}_{c}$. Two different cases are considered in the following. Firstly if the stress state lies below the limit surface $\mathrm{M}^{p c}$, the yield surface is subject to kinematic hardening, namely the back-stress ratio increases or decreases, $\dot{\alpha} \neq 0$. This is referred as mechanism 1. If the reduced deviatoric stress is greater than the fatigue threshold, namely $\xi>\mathrm{M}^{p c}$, mechanism 1 also involves isotropic softening of the cohesion, namely $\dot{\mathrm{p}_{c}}<0$.

On the other hand, if the stress state lies on the limit surface $\mathrm{M}^{l}$, it is not allowed to overcome it. Therefore there is no kinematic hardening, $\dot{\alpha}=0$. However isotropic cohesion softening continues, $\dot{\mathrm{p}}_{c}<0$. This is referred as mechanism 2 in the following. In both cases all surfaces are subject to the same isotropic hardening on $\mathrm{p}_{c}$, namely their apex remains common.

The kinematic hardening law of the yield surface reads

$$
\dot{\alpha}=\dot{\lambda} h\left(\alpha^{b}-\alpha\right)\left|\alpha^{b}-\alpha\right|^{n_{\alpha}}=\dot{\lambda} h_{1},
$$

where $n_{\alpha}$ is a parameter that rules the stiffness and brittleness of the material, and $\mathrm{h}$ is defined as (Taiebat \& Dafalias, 2008)

$$
h=\frac{b_{0}}{\left(\mathbf{M}^{b}\left(1+1 / \delta^{l}\right)-2 \mathbf{M}^{y}-\left(\alpha^{b}-\alpha\right)\right)^{2}},
$$


where $b_{0}$ is a material parameter. The definition of the $\alpha^{b}$ variable depends on the sign of deviatoric stress increment $\mathrm{d} q$

$$
\begin{array}{ll}
\alpha^{b}=\mathbf{M}^{b}-\mathbf{M}^{y} & \mathrm{~d} q>0, \\
\alpha^{b}=-\mathbf{M}^{b} / \delta^{l}+\mathbf{M}^{y} & \mathrm{~d} q<0 .
\end{array}
$$

Such a definition allows different stiffness in loading and unloading.

The isotropic softening rule simply reads

$$
\dot{\mathrm{p}}_{c}=\dot{\lambda} A_{c 1}\left(\mathrm{p}_{\text {res }}-\mathrm{p}_{c}\right)\left\langle|\alpha|-\left|\alpha^{p c}\right|\right\rangle\left|\alpha-\alpha^{p c}\right|^{n_{p c}}=\dot{\lambda} h_{2},
$$

where $A_{c 1}$ and $n_{p c}$ are parameters ruling the rate of decohesion, $\mathrm{p}_{\text {res }}$ is the residual cohesion after full damage, the operator $\langle X\rangle=0.5(|X|+X)$ is the Mc Cauley brackets and

$$
\begin{array}{ll}
\alpha^{p c}=\mathbf{M}^{p c}-\mathbf{M}^{y} & \mathrm{q}>0, \\
\alpha^{p c}=-\mathbf{M}^{p c} / \delta^{l}+\mathbf{M}^{y} & \mathrm{q}<0 .
\end{array}
$$

When the yield surface reaches the limit one, namely $\mathbf{M}^{y}+\alpha=\mathbf{M}^{l}, \alpha$ has reached its maximum value, $\dot{\alpha}=0$. Parameter $A_{c 2}$ is used instead of $A_{c 1}$ in order to control the rate of cohesion decrease.

The hardening laws are written in compact form such that

$$
\dot{\mathbf{v}}=\left[\begin{array}{c}
\dot{\alpha} \\
\dot{\mathrm{p}}_{c}
\end{array}\right]=\dot{\lambda}\left[\begin{array}{c}
h_{1} \\
h_{2}
\end{array}\right]=\dot{\lambda} \mathbf{H} .
$$

\subsection{Plastic multiplier}

Assuming the classical additive decomposition of strain between plastic and elastic components (Simo \& Hughes, 1998), the triaxial stress-strain relation is written

$$
\dot{\mathbf{s}}=\mathbf{E} \cdot\left(\dot{\mathbf{e}}-\dot{\mathbf{e}}^{p}\right)
$$

where

$$
\mathbf{E}=\left[\begin{array}{cc}
2 \mathrm{G} & 0 \\
0 & \mathrm{~K}
\end{array}\right]
$$

where $\mathrm{G}$ is the shear modulus and $\mathrm{K}$ the bulk modulus. The consistency condition is then written

$$
\dot{f}^{y} \equiv\left[\frac{\partial f^{y}}{\partial \mathbf{s}}\right]^{T} \cdot \dot{\mathbf{s}}+\left[\frac{\partial f^{y}}{\partial \mathbf{v}}\right]^{T} \cdot \dot{\mathbf{v}}=0
$$

Inserting Equations (12), (20) and (21) into Equation (23) leads to the following expression of the plastic multiplier

$$
\dot{\lambda}=\frac{\left[\frac{\partial f}{\partial \mathbf{s}}\right]^{T} \cdot \mathbf{E} \cdot \dot{\mathbf{e}}}{\left[\frac{\partial f}{\partial \mathbf{s}}\right]^{T} \cdot \mathbf{E} \cdot \mathbf{G}-\left[\frac{\partial f}{\partial \mathbf{v}}\right]^{T} \cdot \mathbf{H}}
$$


where

$$
\left[\frac{\partial f}{\partial \mathbf{s}}\right]^{T}=\left[\frac{\partial f^{y}}{\partial q} \frac{\partial f^{y}}{\partial p}\right]
$$

and

$$
\left[\frac{\partial f}{\partial \mathbf{v}}\right]^{T}=\left[\frac{\partial f^{y}}{\partial \alpha} \frac{\partial f^{y}}{\partial \mathrm{p}_{c}}\right]
$$

\subsection{Implementation}

The equations are implemented in a set of Matlab routines using a forward Eulerscheme. This scheme is not the most efficient but is accurate enough provided the strain steps are sufficiently small. In addition a correction step to ensure the stress state lies on the yield surface is performed at the end of each iteration.

\subsection{Extension to multiaxial formulation}

The constitutive law is presented in triaxial notations, which is suitable for simulation of uniaxial or triaxial tests. However modelling of real cases studies require the development of a 3D stress state model. The full development of a multiaxial model is out of the scope of this paper. However generalisation of the model to a multiaxial formulation can be carried out following methodology proposed in (Taiebat \& Dafalias, 2008). All the equations are systematically rewritten as function of tensors. All surfaces are expressed as a function of $\mathbf{s}$, the deviatoric stress tensor and the back-stress variable $\alpha$ becomes a second-order tensor. The integration of the constitutive law requires a more complex integration scheme. We recommend the explicit integration scheme with automatic control error presented in (Sloan et al., 2001).

\section{Validation of the model}

The objective of this section is to prove the capability of the model to reproduce different types of experimental results. In the following, three different materials are investigated: Lorano marble, a sandstone and the Lac du Bonnet granite. The choice of these three materials is mainly based on the availability of results published in the literature. Different types of experiments are calibrated: simple compression, triaxial or damage-controlled. The focus is mainly placed on the reproduction of cyclic rather than monotonic results. In addition, simulations consider only a static loading and viscous effects are not taken into account. A final parametric study exhibits the effect of the three main parameters affecting cyclic loading. 


\subsection{Calibration process}

Calibrating material parameters for such a constitutive law is not straightforward. Many experiments are necessary for that purpose but are not always provided all together in the literature. Some model parameters are interrelated and may have similar or opposite effects on results. Therefore the optimisation process may be carried out manually in a trial and error process. All parameters are listed in Table 1 together with experiments necessary to calibrate them.

The full determination of parameters requires many uniaxial, triaxial, monotonic and cyclic experiments. Uniaxial monotonic experiment is used to determine classical elastic (E, $\nu$ ) parameters and slope of the failure criterion $\left(\mathrm{M}^{l}\right)$. The opening of the elastic zone depends on $\mathrm{M}^{y}$ and may be defined within the range 0.0.5-0.1. Cohesion $\mathrm{p}_{c}$ is estimated as an average parameter but is rigorously an internal variable, representative of the state of damage of the sample. Therefore it could be modified depending on the sample for an identical material. Similarly $\alpha$ is another internal variable representing a load induced anisotropy. It is assumed equal to zero initially. The elastic parameters are assumed constant during loading. Therefore results obtained are assumed to be valid only in a limited range of confining pressure. In the following the hypothesis of identical compression and traction strength is also assumed, namely $\delta_{l}=1$, because there were no extension tests available for the considered rock materials. However it should be noted that results are not influenced since only compression tests are investigated. If extension triaxial tests are available, it is possible to define a different $\delta_{l}$ value. Finally a purely associated deviatoric response is assumed, leading to $A_{q}=1$ in Equation (12). On the contrary the volumetric plastic behaviour is non-associated and depends on the dilatancy parameter $A_{d}$.

Kinematic hardening of the internal variable $\alpha$ depends on the slope of the bounding surface $\mathbf{M}^{b}$, the exponent $n_{\alpha}$ and a stiffness parameter $b_{0}$. These parameters rule the non-linear behaviour of the material. Similarly parameters $n_{p c}, A_{c 1}$ and $A_{c 2}$ (postpeak) rule the cohesion degradation (softening of $\mathrm{p}_{c}$ ). All of these parameters must be calibrated as a best-fit of experimental results.

The $\mathrm{M}^{p c}$ parameter represents the fatigue limit. It indeed requires many constant cycles experiment to be accurately captured. However results provided in the literature indicate that the fatigue limit may lie between 60 to 70 percents of the peak stress. Therefore a good starting point for this value is equal to $0.7 \mathrm{M}^{l}$.

Parameters calibrated for all materials are provided in Table 3 in the appendix A.

In addition experimental results may be highly variable due to the heterogeneity, damaging of samples during drilling and/or anisotropy of the material. Therefore results are not very reproducible and it is difficult to predict a priori the peak strength of a given rock sample. Subsequently the cyclic amplitude to monotonic peak stress ratio is not easily obtained and cyclic results are difficult to compare. A method to overcome this problem was recently proposed by Taheri et al. (2016).

Due to the experimentally observed complexity, heterogeneity and variability of rock materials, it is not possible to reproduce perfectly all the results of monotonic and cyclic tests for a single set of parameters. In this work we decided to focus on the cyclic experiments for the determination of a set of parameters. 


\subsection{Characterisation of rock materials}

Lorano marble belongs to the family of white Carrara marble and is one of the most widely used varieties. It is composed of over than $99 \%$ of calcium carbonate. It has a homoblastic arrangement and is composed of regularly shaped grains with straight or gently curbing boundaries (Royer-Carfagni \& Salvatore, 2000). Tested cylindrical specimens reported in this paper are $10 \mathrm{~cm}$ long and $4 \mathrm{~cm}$ in diameter. The loading rate of the test is about $1-2 \mathrm{MPa} / \mathrm{s}$ and of the order of one cycle per minute. The experiment investigated is a constant amplitude cyclic simple compression.

Characteristics of the tested sandstone are not reported in the reference paper (Liu $\& \mathrm{He}, 2012)$. The samples have a diameter to length ratio of 1:2 with an average diameter of $48.9 \mathrm{~mm}$. Cycles are applied at a frequency of $1 \mathrm{~Hz}$. The investigated experiment is a constant amplitude cyclic triaxial test with a confining pressure equal to $10 \mathrm{MPa}$.

The Lac du Bonnet granite is medium to coarse grained and composed of approximately $30 \% \mathrm{~K}$-feldspar, $30 \%$ plagioclase, $30 \%$ quartz and $10 \%$ mafic minearls, mainly biotite. The average grain size of the medium-grained granite is about $3-4 \mathrm{~mm}$. Results reported in this paper were obtained from the 420 level of AECL's Underground Research Laboratory (Martin \& Chandler, 1994). Uniaxial and triaxial post-failure tests were carried out on 63-mm diameter grey samples. The stress rate is equal to $0.75 \mathrm{MPa} / \mathrm{s}$. The experiment investigated is a damage controlled triaxial test with a confining pressure equal to $15 \mathrm{MPa}$.

\subsection{Lorano Marble}

Results of a monotonic simple compression simulation is firstly compared with respect to published data (Royer-Carfagni \& Salvatore, 2000). The objective is twofold: validating the model and illustrating its basic working. The reference cyclic paper (Royer-Carfagni \& Salvatore, 2000) does not provide monotonic triaxial tests at different confining pressures. Therefore friction angle, cohesion and elastic parameters are estimated and compared with the literature (Dal Pino et al., 1999; Royer-Carfagni \& Salvatore, 2000; Cattaneo \& Labuz, 2001; Papamichos et al., 2004; Stavropoulou et al., 2004; Ferrero et al., 2009).

Results are in good agreements with experimental results as shown in Figures 9 and 10. This material presents a relatively large amount of plastic strain before failure, with respect to the other investigated rocks, that is correctly reproduced. Brittle failure is also captured in terms of both peak resistance $(\sim 85 \mathrm{MPa})$ and strain $(\sim 0.22 \%)$. No data are available on the post-peak behaviour, therefore it is simulated for three different values of $A_{c 2}$. The brittleness of failure increases with this parameter.

Volumetric behaviour before peak is depicted in Fig10. Behaviour is mainly dilative due to crack opening. Data and simulations are in good agreement.

The evolution of internal variables is reported in Fig11. During the first part of the simulation, $\alpha$ nonlinearly increases, indicating kinematic hardening. In the meantime, the cohesion internal variable $\mathrm{p}_{c}$ is only slightly affected. When $\alpha=\mathrm{M}^{l}-\mathrm{M}^{y}$ the limit surface is reached and $\alpha$ remains constant. However $\mathrm{p}_{c}$ strongly decreases 
indicating failure. The slope discontinuity is due to the change from mechanism 1 to mechanism 2. In this case, $h_{1}$ changes from a value different from zero to zero, affecting plastic multiplier computation in Equation (24) and generating this sharper cohesion decrease.

The evolution of the internal variables affects the position of the yield surface as represented in Fig12. The elastic zone (in grey), the trace of the limit surface (solid black line), the trace of $\alpha$ (dashed line), the stress path (dashed and pointed line) and the current stress state (circle marker) are represented in this figure for three different vertical strain $\epsilon_{1}$ of the monotonic simple compression simulation. In the top figure, only mechanism 1 is activated, $\alpha$ increases (kinematic hardening, Eq. 13). In the meantime cohesion $\mathrm{p}_{c}$ has only slightly decreased (isotropic softening, Eq. 17). In the second figure, the stress states gets into contact with the limit surface. Changes in cohesion $\mathrm{p}_{c}$ are still very limited since the stress states lied below the limit surface. The last figure represents the post-peak behaviour, $\alpha$ is constant but $\mathrm{p}_{c}$ decreases strongly, causing softening.

According to this model, the experimentally measured cohesion at peak is different from the initial cohesion used for $\mathrm{p}_{c}$. This could complicate the calibration process. However since cohesion is only slightly modified during monotonic loading, the measured value at peak may serve as a good guess for its initialisation.

The best fit for cyclic results is provided in Figures 13 and 14. The first figure represents the stress-strain evolution and could be compared with Fig1. It is impossible to superpose both figures (it would be impossible to read) or to compare each cycle independently (it would need a lot of figures). Qualitatively the physical trends are correctly reproduced. The total number of cycles and final plastic strain are correctly captured by the simulation. Lateral strain is larger than the axial one as observed experimentally. Finally the cycles are progressively opening, indicating a larger amount of plasticity as the stress path approaches failure.

Accumulation of strain can be compared through a strain indicator computed for each cycle. Maximum volumetric strain reached over a cycle $\mathrm{N}$ may be quantified by (Royer-Carfagni \& Salvatore, 2000)

$$
\Delta_{\max }(N)=\max _{\text {cycle } N}\left[\frac{\epsilon_{1}+\epsilon_{3}}{2}\right],
$$

Similarly the minimum value $\Delta_{\min }(N)$ may be computed. Indicators evolution with respect to the number of cycles is provided in Fig14. Simulated and experimental results are in relatively good agreement, with respect to final cycle number (45 numerically and 51 experimentally) and strain. The general trend is accumulation of negative strain, due to microcrack opening. A shear strain indicator could be computed considering $\left|\epsilon_{1}-\epsilon_{3}\right|$ in Equation 27. Experimental and simulated results match similarly and are not presented. Therefore it could be concluded that the accumulation of plastic strain cycle after cycle is correctly captured.

The evolution of cohesion variable $\mathrm{p}_{c}$ with axial strain is provided in Fig15. It shows that the cyclic loading progressively weakens the material and degrades cohesion. Finally the imposed stress path reached the limit surface and failure occurs. By 
comparison with Fig11, cohesion is significantly decreased before the second mechanism is activated.

Optimisation of parameters for the cyclic experiment requires modification of three values of the initial set of parameters provided in Table 3. Firstly as mentioned in section 2, rock samples used for monotonic and cyclic tests do not have the same strength properties. Therefore the cohesion parameter $\mathrm{p}_{c}$ reflecting indirectly the initial damage is set up to $34 \mathrm{MPa}$.

Stiffness $b_{0}$ and degradation $A_{c 1}$ parameters are modified to $410^{5}$ and 400 respectively. Calibrating these parameters on monotonic tests only always lead to overestimation of plastic strain during cyclic loading. Physically it is assumed that the rock material hardens during the first or few first cycles and softens afterwards. In order to simplify the model formulation, this fast hardening is neglected and only final hardened parameters are calibrated. This does not affect comparison of the global tendency.

\subsection{Sandstone}

Cyclic triaxial experiments on a sandstone are provided below from the original paper (Liu \& He, 2012). Monotonic results characterising the material are provided in Fig16. Therefore elastic and strength parameters could be calibrated directly from data provided in the paper. Young modulus only slightly varies with confining pressure. The post-peak behaviour is very sharp at low confining pressure but is smoother at higher confining pressure. Calibrated parameters on the cyclic triaxial test with a confining pressure equal to $10 \mathrm{MPa}$ are provided in Table 3.

The reference paper does not detail how the cyclic amplitude was chosen for each presented experiment (Liu \& He, 2012). Moreover it seems that the cyclic load is always larger than the reporter monotonic peak strength. Therefore it is assumed the cyclic load is $15 \mathrm{MPa}$ lower than the peak strength in this section.

Simulation of monotonic and cyclic trixial test (confining pressure equal to $10 \mathrm{MPa}$ ) and an experimental monotonic tests are compared in Fig17. Once again, parameters are calibrated to reproduce the cyclic behaviour rather than the monotonic test. Therefore monotonic simulation is stiffer than observed experimentally.

Once again, it is difficult to compare the effect of each cycle independently. Therefore simulated axial and volumetric residual strain corresponding to each cycle are compared with experimental ones in Figures 18 and 19. Experimental results are corrected to start from 0 at the beginning of the test. This neglects the effect of the first cycle which is not reproduced by the model as previously discussed. Subsequently comparison is focused here on the following accumulation.

Comparison of simulation and experiment can be based on different criteria: slope of the stationary phase, number of cycle to failure, final residual strain, axial or volumetric strain. In this work we focus on the slope of the stationary phase and number of cycles to failure bof both axial and volumetric residual strain

They are both well captured by the simulations. Final strain at the end of the experiment and activation of the second mechanism are different. For instance in Fig18, 
$\epsilon_{1, \text { residual }}$ is equal to $0.15 \%$ when the stress path crosses the limit surface while it reaches $0.3 \%$ at the end of the experiment. For the simulation, further accumulated strain is due to the post-peak behaviour. For the experiment, half of the final strain is accumulated during the last few cycles. It is assumed that they may be assimilated to failure.

\subsection{Lac du Bonnet granite}

Lac du Bonnet granite is a well studied rock material (Martin \& Chandler, 1994; Chow et al., 1995; Martin, 1997; Eberhardt et al., 1999a,b), exhibiting clearly a brittle behaviour as shown in Fig20. Elastic and failure parameters are calibrated with respect to literature. However samples presented by Martin \& Chandler (1994) are known to be initially damaged due to sampling, which modifies their properties with respect to literature. It is shown that the failure locus is described by a Hoek-Brown criterion (Hajiabdolmajid \& Kaiser, 2002). However it is assumed that a Drucker Prager limit surface will be a reasonable approximation in the considered range of confining pressures. Calibrated parameters are provided in Table 3.

Monotonic simulation and experiment at a confining pressure equal to $15 \mathrm{MPa}$ are compared in Fig21. The behaviour is relatively stiff and only few plastic strain are observed before brittle failure. The first part of the post-peak behaviour is well reproduced despite the residual strain is lower experimentally. This may result from a degradation of the friction angle. It should also be noted that a too high $A_{c 2}$ parameter may lead to snapback phenomenon which can not be captured with the integration scheme used in this work.

Driving of the damage controlled test presented in Fig6 is complex. Achieving such a special driving numerically is not easy. The numerical integration of the constitutive equation is strain driven and divided into $\Delta \epsilon_{1}$ increments. Before the peak it is assumed the stress reversal occurs every $N \Delta \epsilon_{1}$ increments. After the peak, it is assumed that only two time steps are allowed when the limit surface is reached.

Stress-strain results of the damage controlled tests are presented in Fig22 along with a post-peak monotonic simulation. They are compared with experimental results (Martin \& Chandler, 1994) provided in Fig6. The trend of the results is well reproduced. The pre-peak cycles generate plastic strain and the peak strength is decreased. Maximum stress reached after the peak fast decrease due to the cohesion's weakening. The monotonic loading is almost an envelope for cyclic results, as expected. The small shift is due to the amount of plastic strain accumulated before peak.

A damage indicator $\omega$ is defined as the volumetric residual strain $\epsilon_{v}^{p}$ reached at the end of the unloading. A comparison of this indicator evolution for both numerical and experimental results is carried out in Fig23. Numerical results do not fit perfectly the experimental points but are in reasonable agreement. The difference in the post peak domain may be mainly due to the driving process which is different numerically and allows less plastic strain before reversal.

It should be noted that comparison in the post-peak zone is subject to caution. Indeed, experimentally cracks are generated and coalesce. Therefore measured results are representative of the rock sample in which stresses and strain are not homogeneous. 
On the contrary numerical results assume homogeneity over a sample.

However the post-peak behaviour must be numerically defined for several reasons in the constitutive law. Firstly a softening regime is necessary to reproduce numerically fracture initiation or strain localisation. Secondly if the constitutive law is applied to the modelling of a real case study, for instance of a cavern or rock pillar, a local failure may happen without leading to a global collapse of the studied problem. Therefore the constitutive law may be defined for such a post peak state.

\subsection{Parameters influencing cyclic response}

A parametric study is provided in the following, based on the Lorano marble cyclic test, in order to illustrate the influence of three parameters affecting cyclic results: $b_{0}$, $A_{c}, \mathrm{M}^{p c}$. The evolution of $\Delta_{\min }$ with the number of cycles up to failure is reported for each parameter and compared with the reference value. The influence of each parameter is summarised in Table 2.

The influence of the fatigue limit $\mathrm{M}^{p c}$ is obvious, as reported in Figure 24. By definition of this model, cohesion is only degraded when the stress path lies outside the fatigue surface $\mathrm{q} /\left(\mathrm{p}+\mathrm{p}_{c}\right)>\mathrm{M}^{p c}$. Therefore increasing the size of this surface reduces the degradation rate of each cycle and increases the number of cycle to failure as well as final strain.

Parameter $b_{0}$ affects the amount of plastic strain that is generated during loading, as reported in Figure 25. Therefore increasing this value, decreases the amount of plastic strain generated during each cycle. Consequently, the number of cycle at failure also increases since the degradation of cohesion is a function of the accumulated plastic strain. The final strain is larger in absolute value since there are more cycles.

Finally the parameter $A_{c}$ affects the rate of cohesion degradation as a function of the plastic strain accumulation. Therefore increasing this value directly leads to a faster degradation of each cycle, a lower number of cycles to failure and final strain, as depicted in Figure 26.

\section{Conclusion}

This paper presents the mathematical formulation of a new constitutive law able to reproduce the cyclic behaviour of brittle rock materials at low confining pressure. It lies on the elastoplastic framework and is based on a bounding surface model developed initially for sands. It is able to reproduce salient features of the monotonic and cyclic behaviour of rock materials

- brittle failure of the material,

- post-peak behaviour,

- accumulation of plastic strain upon cyclic load,

- progressive opening of the cycles,

- degradation of the cohesion,

- fatigue resistance of the material. 
The basic idea of this model assumes that cyclic loading progressively degrades cohesion of a rock material even if the load applied is lower than its monotonic resistance, namely if the loading lies within the limit surface. A fatigue limit is incorporated within the formulation to take into account the fatigue resistance observed experimentally, namely the maximum load below which there is no degradation of the resistance. The isotropic mechanism (cohesion degradation) is coupled with a kinematic mechanism to reproduce accumulation of plastic strain during cycling. The model is formulated in triaxial notations and implemented in a Matlab set of routines using a forward Euler scheme.

The new model is validated against three different rock materials (Lorano marble, a sandstone, Lac du Bonnet granite) and diverse monotonic (simple compression, triaxial compression) and cyclic tests (simple compression, triaxial compression, constant amplitude, damage controlled). It is shown that a set of parameters can be obtained in any case to reproduce the trend of cyclic experiments, namely to capture the residual strain or number of cycle to failure. Therefore the model is proven to be suitable to reproduce such a behaviour.

However it is also highlighted that calibration process is not straightforward. The first issue is mainly the lack of data related to a given material. Due to the relative complexity of the model, numerous triaxial tests in compression and also in extension should be necessary to calibrate failure parameters. Similarly sufficient cyclic tests should be carried out to derive the fatigue strength and cyclic degradation of the material. The second major issue is the heterogeneity and variability of rock samples. Therefore it is often uneasy to compare results from different samples, between monotonic and cyclic or simply between two cyclic tests.

This model incorporates many features of the monotonic and cyclic behaviours of rock materials. However it does not reproduce all physical phenomena and is mainly applicable under some hypotheses. Elastic properties of the material are considered isotropic as well as cohesion of the material while some anisotropy is likely. Rate and viscous effects are not considered, therefore parameters correspond to a given strain rate.

The quality of the model may be improved in several ways, at the cost of additional parameters to be calibrated or implementation complexity increase. Firstly the shape of the limit surface may be modified. Indeed it is shown that the Hoek-Brown criterion is more relevant than a Drucker-Prager one to represent failure locus (Hoek \& Brown, 1980; Hajiabdolmajid \& Kaiser, 2002). However the implementation of such a criterion would be more complex since the yield surface should be homothetic to this surface in order to avoid overlap. In addition a cap should be applied to close the surface and allow plasticity upon constant stress ratio loading. Different types of yield surfaces are investigated by Taiebat \& Dafalias (2010) and may be adopted for improving the present model.

In this model it is assumed cohesion degrades progressively but friction angle remains constant. However it is shown that friction is progressively hardening as cohesion decreases (Martin \& Chandler, 1994; Hajiabdolmajid \& Kaiser, 2002). This could be included within the model by introducing a hardening law of the limit surface. This mechanism could allow a larger plastic strain accumulation for monotonic and first cycle of cyclic loading. In addition damaging of elastic properties, despite not obser- 
ved in any cyclic experiment may represent another major improvement.

In the opinion of the authors, the last very important issue is modification of parameters from intact rock sample to rock mass, as studied by Hoek \& Brown (1997). However the fundamental objective of a constitutive law is to study larger structures such as caverns, tunnels or pillars. Therefore parameters should be scaled to correspond to the rock mass, which has a lower strength due to heterogeneities and discontinuities. The use of more complex constitutive laws using more parameters makes this process more difficult.

\section{Acknowledgement}

The authors gratefully acknowledges the financial support from Walloon Region (Belgium) and the SMARTWATER project. The first author would like to warmly thank the Pr. Derek Martin for his encouragement and data he provided.

\section{A Set of parameters}

All parameters calibrated for the validation of the three different materials are reported in Table 3 .

\section{References}

Alliche, A. (2004). Damage model for fatigue loading of concrete. International Journal of Fatigue 26, No. 9, 915-921, doi:10.1016/j.ijfatigue.2004.02.006.

Attewell, P. \& Farmer, W. (1973). Fatigue behaviour of rock. International Journal of Rock Mechanics and Mining Sciences 10, 1-9.

Bastian, T., Connelly, B., Lazo Olivares, C., Yfantidis, N. \& Taheri, A. (2014). Progressive Damage of Hawkesbury Sandstone Subjected to Systematic Cyclic Loading. Mining Education Australia Journal of Research Projects Review 3, 7-14.

Benz, T. \& Schwab, R. (2008). A quantitative comparison of six rock failure criteria. International Journal of Rock Mechanics and Mining Sciences 45, 1176-1186.

Bieniawski, Z. (1967a). Mechanism of brittle fracture of rock: PART I Theory of the fracture process. International Journal of Rock Mechanics and Mining Sciences 4, 395-406.

Bieniawski, Z. (1967b). Mechanism of brittle fracture of rock: PART II Experimental studies. International Journal of Rock Mechanics and Mining Sciences 4, 407-423.

Brantut, N., Heap, M., Meredith, P. \& Baud, P. (2013). Time-dependent cracking and brittle creep in crustal rocks: A review. Journal of Structural Geology 52, 17-43, doi:10.1016/j.jsg.2013.03.007.

Breccolotti, M., Bonfigli, M., D’Alessandro, A. \& Materazzi, A. (2015). Constitutive modeling of plain concrete subjected to cyclic uniaxial compressive loading. Construction and Building Materials 94, 172-180, doi:10.1016/j.conbuildmat.2015.06.067.

Burdine, N. (1963). Rock failure under dynamic loading conditions. Society of Petroleum Engineers Journal 3, No. 01, 1-8.

Cattaneo, S. \& Labuz, J. (2001). Damage of marble from cyclic loading. Journal of materials in civil engineering 13, No. December, 459-465.

Cerfontaine, B., Collin, F. \& Charlier, R. (2015). Numerical modelling of transient cyclic vertical loading of suction caissons in sand. Géotechnique 65, No. 12.

Chen, H., Cong, T., Yang, W., Tan, C., Li, Y. \& Ding, Y. (2009). Progress in electrical energy storage system: A critical review. Progress in Natural Science 19, No. 3, 291-312, doi: 10.1016/j.pnsc.2008.07.014 
Chow, T. M., Meglis, I. L. \& Young, R. P. (1995). Progressive microcrack development in tests on Lac du Bonnet granite-II. Ultrasonic tomographic imaging. International Journal of Rock Mechanics and Mining Sciences and 32, No. 8, 751-761, doi:10.1016/0148-9062(95)00015-9.

Dafalias, Y. (1986). Bounding surface plasticity. i: Mathematical foundation and hypoplasticity. Journal of Engineering Mechanics 112, No. 9, 966-987.

Dafalias, Y. \& Manzari, M. (2004). Simple plasticity sand model accounting for fabric change effects. Journal of Engineering Mechanics 130, No. 6, 622-634.

Dafalias, Y., Papadimitriou, A. \& Li, X. (2004). Sand plasticity model accounting for inherent fabric anisotropy. Journal of Engineering Mechanics 130, No. 11, 1319-1333.

Dafalias, Y. \& Taiebat, M. (2016). SANISAND-Z: Zero elastic range sand plasticity model. Géotechnique 66, No. 12, 999-1013.

Dal Pino, R., Narducci, P. \& Royer-Carfagni, G. (1999). A SEM investigation on fatigue damage of marble. Journal of materials science letters 18, 1619-1622.

Eberhardt, E., Stead, D. \& Stimpson, B. (1999a). Quantifying progressive pre-peak brittle fracture damage in rock during uniaxial compression. International Journal of Rock Mechanics and Mining Sciences 36, No. 3, 361-380, doi:10.1016/S0148-9062(99)00019-4.

Eberhardt, E., Stimpson, B. \& Stead, D. (1999b). Effects of Grain Size on the Initiation and Propagation Thresholds of Stress-induced Brittle Fractures. Rock Mechanics and Rock Engineering 32, No. 2, 8199, doi:10.1007/s006030050026.

Erarslan, N., Alehossein, H. \& Williams, D. J. (2014). Tensile Fracture Strength of Brisbane Tuff by Static and Cyclic Loading Tests. Rock Mechanics and Rock Engineering 47, No. 4, 1135-1151, doi: 10.1007/s00603-013-0469-5.

Erarslan, N. \& Williams, D. J. (2012). Investigating the Effect of Cyclic Loading on the Indirect Tensile Strength of Rocks. Rock Mechanics and Rock Engineering 45, No. 3, 327-340, doi:10.1007/s00603011-0209-7.

Ferrero, A., Migliazza, M. \& Spagnoli, A. (2009). Theoretical modelling of bowing in cracked marble slabs under cyclic thermal loading. Construction and Building Materials 23, No. 6, 2151-2159.

Førsund, F. (2015). Hydropower economics, vol. 217. Springer.

Gatelier, N., Pellet, F. \& Loret, B. (2002). Mechanical damage of an anisotropic porous rock in cyclic triaxial tests. International Journal of Rock Mechanics and Mining Sciences 39, No. 3, 335-354, doi: 10.1016/S1365-1609(02)00029-1.

Ghamgosar, M. \& Erarslan, N. (2015). Experimental and Numerical Studies on Development of Fracture Process Zone (FPZ) in Rocks under Cyclic and Static Loadings. Rock Mechanics and Rock Engineering 49, No. 3, 893-908, doi:10.1007/s00603-015-0793-z.

Haimson, B. \& Kim, C. (1971). Mechanical behavior of rock under cyclic fatigue. Rock Mechanics and Rock Engineering, 845-862.

Hajiabdolmajid, V. \& Kaiser, P. (2002). Brittleness of rock and stability assessment in hard rock tunneling. Tunnelling and Underground Space Technology 18, No. 1, 35-48, doi:10.1016/S0886-7798(02)001001.

Hashiguchi, K. (2009). Elastoplasticity theory. Springer_verlag Berlin Heidelberg.

Hoek, E. \& Brown, E. (1980). Underground excavations in rock. London: The institution of mining and metallurgy.

Hoek, E. \& Brown, E. (1997). Practical estimates of rock mass strength. International Journal of Rock Mechanics and Mining Sciences 34, No. 8, 1165-1186, doi:10.1016/S1365-1609(97)80069-X

Hueckel, T. (1991). Damping, cyclic strain buildup and fatigue of rocks a generalized ramberg-osgood approach. Computers and Geotechnics 12, No. 3, 235-269.

Khaledi, K., Mahmoudi, E., Datcheva, M. \& Schanz, T. (2016a). Stability and serviceability of underground energy storage caverns in rock salt subjected to mechanical cyclic loading. International Journal of Rock Mechanics and Mining Sciences 86, 115-131, doi:10.1016/j.ijrmms.2016.04.010.

Khaledi, K., Mahmoudi, E., Datcheva, M. \& Schanz, T. (2016b). Stability and serviceability of underground energy storage caverns in rock salt subjected to mechanical cyclic loading. International Journal of Rock Mechanics and Mining Sciences 86, No. 15, 115-131, doi:10.1016/j.ijrmms.2016.04.010.

Li, N., Zhang, P., Chen, Y. \& Swoboda, G. (2003). Fatigue properties of cracked, saturated and frozen sandstone samples under cyclic loading. International Journal of Rock Mechanics and Mining Sciences 40, No. 1, 145-150, doi:10.1016/S1365-1609(02)00111-9.

Li, X. \& Dafalias, Y. (2012). Anisotropic critical state theory: role of fabric. Journal of Engineering Mechanics 138, No. 3, 263-275. 
Liu, E. \& He, S. (2012). Effects of cyclic dynamic loading on the mechanical properties of intact rock samples under confining pressure conditions. Engineering Geology 125, 81-91, doi: 10.1016/j.enggeo.2011.11.007.

Liu, J., Xie, H., Hou, Z., Yang, C. \& Chen, L. (2014). Damage evolution of rock salt under cyclic loading in unixial tests. Acta Geotechnica 9, No. 1, 153-160, doi:10.1007/s11440-013-0236-5.

Mahmoudi, E., Khaledi, K., Miro, S., König, D. \& Schanz, T. (2016). Probabilistic Analysis of a Rock Salt Cavern with Application to Energy Storage Systems. Rock Mechanics and Rock Engineering I, doi:10.1007/s00603-016-1105-y.

Manzari, M. \& Dafalias, Y. (1997). A critical state two-surface plasticity model for sands. Geotechnique 47, No. 2, 255-272.

Martin, C. \& Chandler, N. (1994). The progressive fracture of lac du bonnet granite. International Journal of Rock Mechanics and Mining Sciences \& Geomechanics Abstracts 31, No. 6, 643-659.

Martin, C. D. (1997). Seventeenth Canadian Geotechnical Colloquium: The effect of cohesion loss and stress path on brittle rock strength. Canadian Geotechnical Journal 34, No. 5, 698-725.

Mazars, J., Hamon, F. \& Grange, S. (2015). A new 3D damage model for concrete under monotonic, cyclic and dynamic loadings. Materials and Structures , 3779-3793doi:10.1617/s11527-014-0439-8.

Mira, P., Tonni, L., Pastor, M. \& Fernandez-Merodo, J. (2009). A generalized midpoint algorithm for the integration of a generalized plasticity model for sands. International Journal for Numerical Methods in Geomechanics 77, 1201-1223, doi:10.1002/nme.

Papamichos, E., Papanicolopulos, S., Larsen, I., Alnæs, L. \& Rescic, S. (2004). Method for in situ, quasi non-destructive diagnosis of mechanical properties and damage of natural building stones. In Gulf Rocks 2004, the 6th North America Rock Mechanics Symposium (NARMS), American Rock Mechanics Association.

Peng, X. \& Meyer, C. (2000). A continuum damage mechanics model for concrete reinforced with randomly distributed short fibers. Computers \& Structures 78, No. 4, 505-515, doi:10.1016/S00457949(00)00045-6.

Pouya, A., Zhu, C. \& Arson, C. (2016). Micro-macro approach of salt viscous fatigue under cyclic loading. Mechanics of Materials 93, 13-31, doi:10.1016/j.mechmat.2015.10.009.

Prevost, J.-H. (1985). A simple plasticity theory for frictional cohesionless soils. Soil Dynamics and Earthquake Engineering 4, No. 1, 9-17.

Prost, G. (1988). Jointing at rock contacts in cyclic loading. International Journal of Rock Mechanics and Mining Sciences and 25, No. 5, 263-272, doi:10.1016/0148-9062(88)90003-4.

Pujades, E., Willems, T., Bodeux, S., Orban, P. \& Dassargues, A. (2016). Underground pumped storage hydroelectricity using abandoned works (deep mines or open pits) and the impact on groundwater flow. Hydrogeology Journal 24, No. 6, 1531-1546, doi:10.1007/s10040-016-1413-z.

Raju, M. \& Kumar Khaitan, S. (2012). Modeling and simulation of compressed air storage in caverns: A case study of the Huntorf plant. Applied Energy 89, No. 1, 474-481, doi: 10.1016/j.apenergy.2011.08.019.

Royer-Carfagni, G. \& Salvatore, W. (2000). The characterization of marble by cyclic compression loading: experimental results. Mechanics of Cohesive-frictional Materials 5, No. 7, 535-563.

Simo, J. \& Hughes, T. (1998). Computational inelasticity. Springer-Verlag, New-York.

Sloan, S. W., Abbo, A. J. \& Sheng, D. (2001). Refined explicit integration of elastoplastic models with automatic error control. Engineering Computations 18, No. 1/2, 121-194, doi: $10.1108 / 02644400110365842$.

Stavropoulou, M., Liolios, P. \& Exadaktylos, G. (2004). Calibration of the Triaxial Hyperbolic MohrCoulomb Elastoplastic Model Parameters on Laboratory Rock Mechanics Tests. International Journal of Geomechanics 12, No. December, 618-631.

Steffen, B. (2012). Prospects for pumped-hydro storage in germany. Energy Policy 45, 420-429.

Suaris, W., Ouyang, C. \& Fernando, V. (1990). Damage model for cyclic loading of concrete. Journal of Engineering Mechanics 116, No. 5, 1020-1035.

Taheri, A., Royle, A., Yang, Z. \& Zhao, Y. (2016). Study on variations of peak strength of a sandstone during cyclic loading. Geomechanics and Geophysics for Geo-Energy and Geo-Resources 2, No. 1, 1-10, doi:10.1007/s40948-015-0017-8.

Taiebat, M. \& Dafalias, Y. (2008). SANISAND: simple anisotropic sand plasticity model. International Journal for Numerical and Analytical Methods in Geomechanics 32, No. March, 915-948.

Taiebat, M. \& Dafalias, Y. (2010). Simple yield surface expressions appropriate for Soil Plasticity. International Journal of Geomechanics 10, No. 4, 161-169. 
Wang, Z., Li, S., Qiao, L. \& Zhang, Q. (2015). Finite element analysis of the hydro-mechanical behavior of an underground crude oil storage facility in granite subject to cyclic loading during operation. International Journal of Rock Mechanics and Mining Sciences 73, 70-81, doi:10.1016/j.ijrmms.2014.09.018.

Wang, Z., Li, S., Qiao, L. \& Zhao, J. (2013). Fatigue Behavior of Granite Subjected to Cyclic Loading Under Triaxial Compression Condition. Rock Mechanics and Rock Engineering 46, No. 6, 1603-1615, doi:10.1007/s00603-013-0387-6.

Wu, J., Li, J. \& Faria, R. (2006). An energy release rate-based plastic-damage model for concrete. International Journal of Solids and Structures 43, No. 3-4, 583-612, doi:10.1016/j.ijsolstr.2005.05.038.

Xiao, J., Ding, D., Jiang, F. \& Xu, G. (2010). Fatigue damage variable and evolution of rock subjected to cyclic loading. International Journal of Rock Mechanics and Mining Sciences 47, No. 3, 461-468, doi:10.1016/j.ijrmms.2009.11.003.

Xiao, J., Ding, D., Xu, G. \& Jiang, F. (2009). Inverted S-shaped model for nonlinear fatigue damage of rock. International Journal of Rock Mechanics and Mining Sciences 46, No. 3, 643-648, doi: 10.1016/j.ijrmms.2008.11.002. 


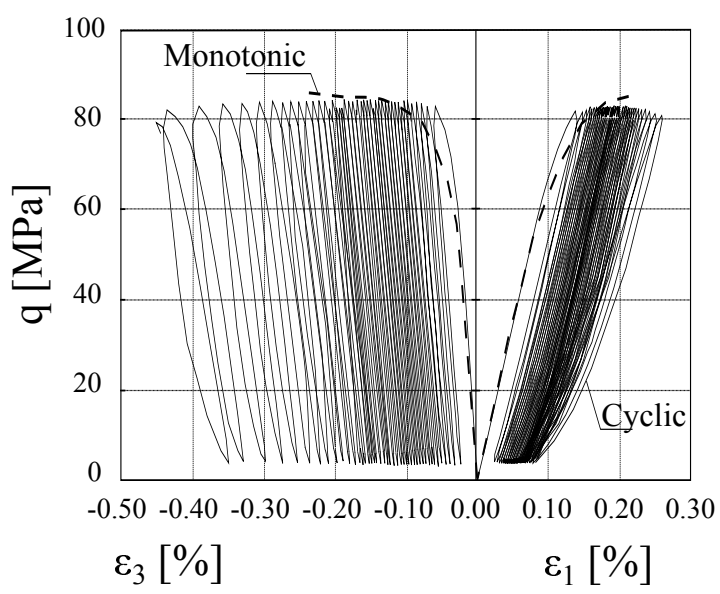

Fig. 1: Monotonic and cyclic simple compression (constant amplitude) tests on Lorano marble, data traced from (Royer-Carfagni \& Salvatore, 2000)

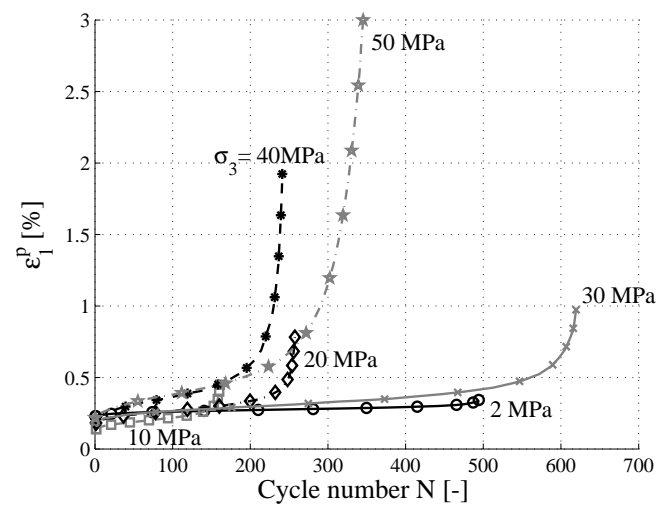

Fig. 2: Cyclic compression triaxial tests at six confining pressures, plastic axial strain $\epsilon_{1}^{p}$ versus cycle number N, sandstone, (Liu \& He, 2012) 


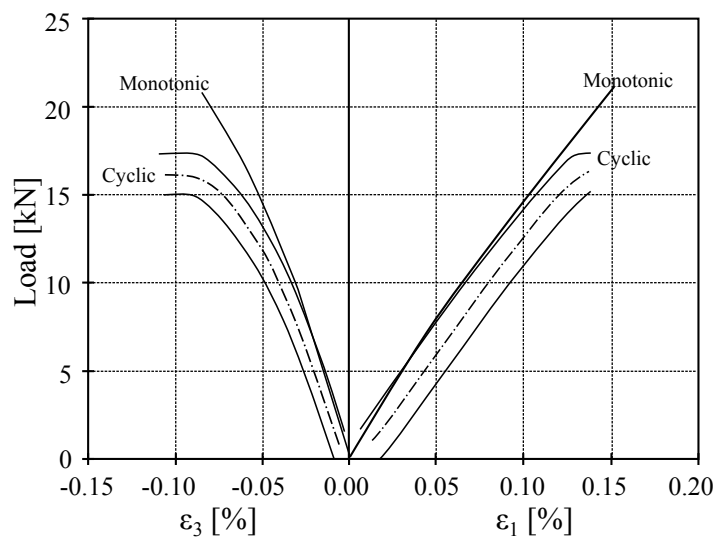

Fig. 3: Comparison of monotonic and cyclic indirect tensile strength results of Brisbane tuff, (Erarslan \& Williams, 2012)

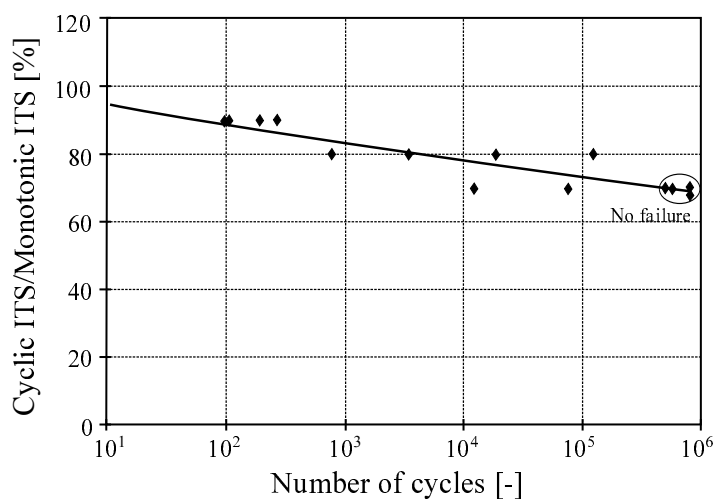

Fig. 4: S-N curve for indirect tensile strength of Brisbane tuff, (Erarslan \& Williams, 2012) 


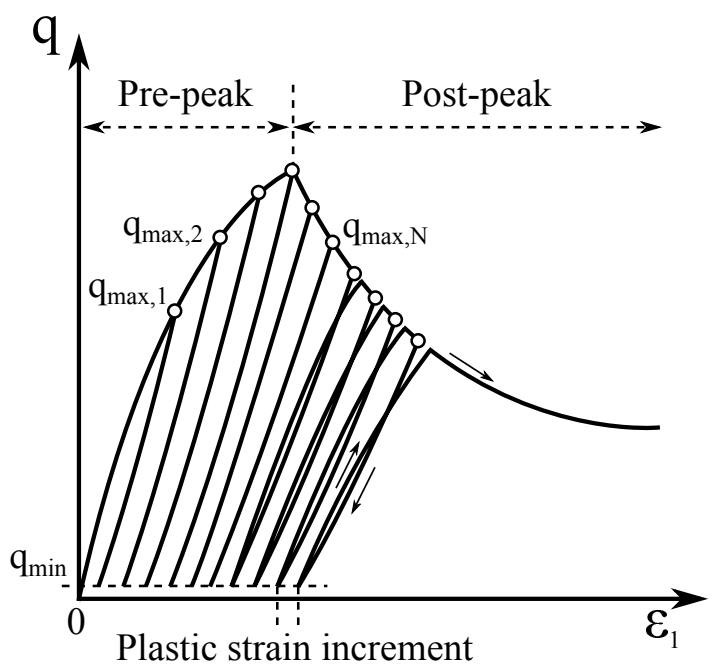

Fig. 5: Sketch of a damage controlled test

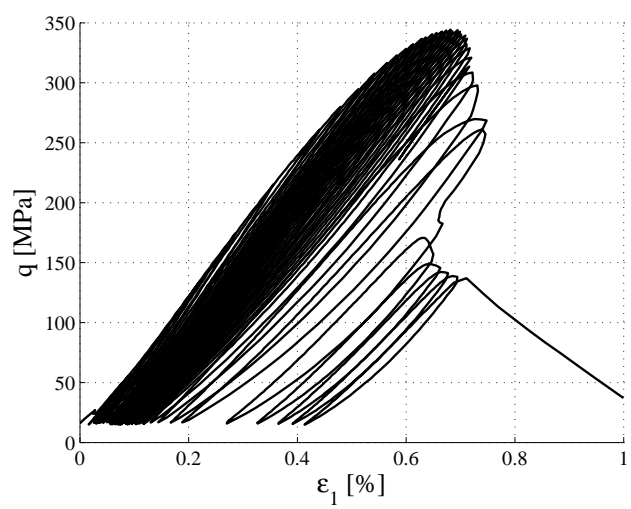

Fig. 6: Damage controlled test on Lac du Bonnet granite, $\sigma_{3}=15 \mathrm{MPa}$, (Martin \& Chandler, 1994)

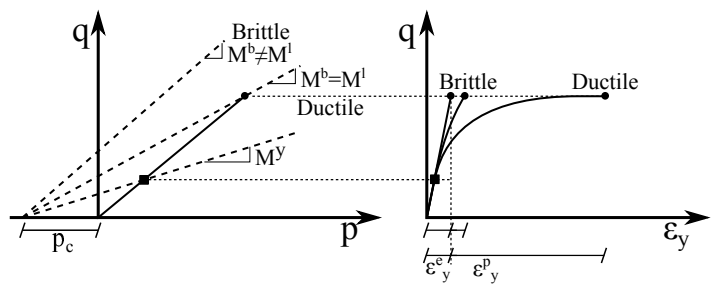

Fig. 7: Difference between ductile and brittle failure, solid line: stress path, square markers: start of plastic strain, circle markers: peak strength 


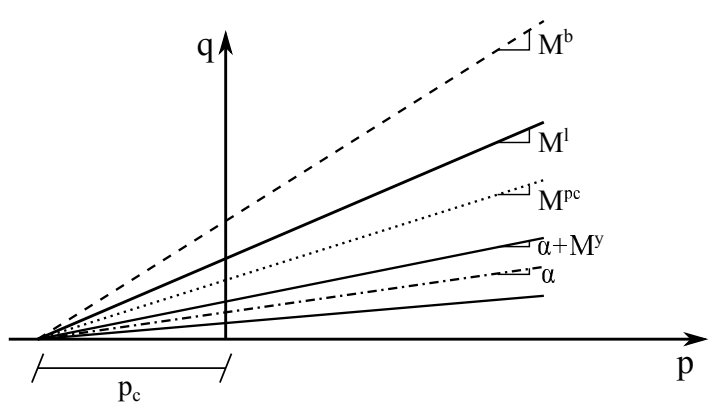

Fig. 8: Description of the different surfaces of the model (compression side $\mathrm{q}>0$ ): $\alpha$ back-stress ratio, $\mathrm{M}^{y}$ yield surface, $\mathrm{M}^{l}$ limit surface, $\mathrm{M}^{b}$ bounding surface, $\mathrm{M}^{p c}$ decohesion surface

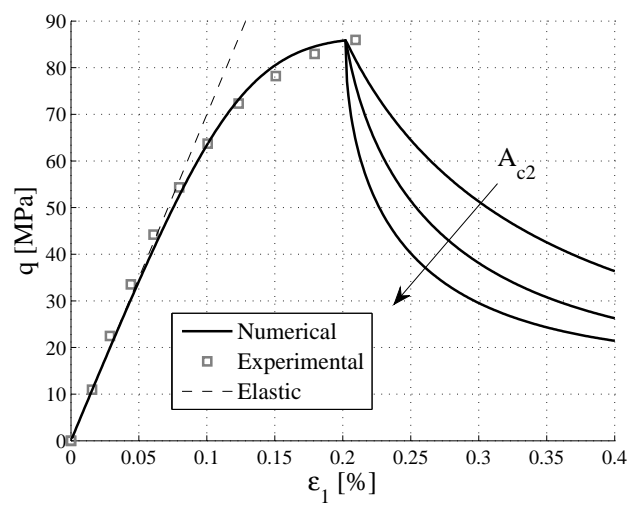

Fig. 9: Comparison of monotonic simple compression simulation and experimental results, deviatoric stress q vs. axial strain $\epsilon_{1}$, Lorano marble, $A_{c 2}=[500,750,1000]$, experimental results from (Royer-Carfagni \& Salvatore, 2000) 


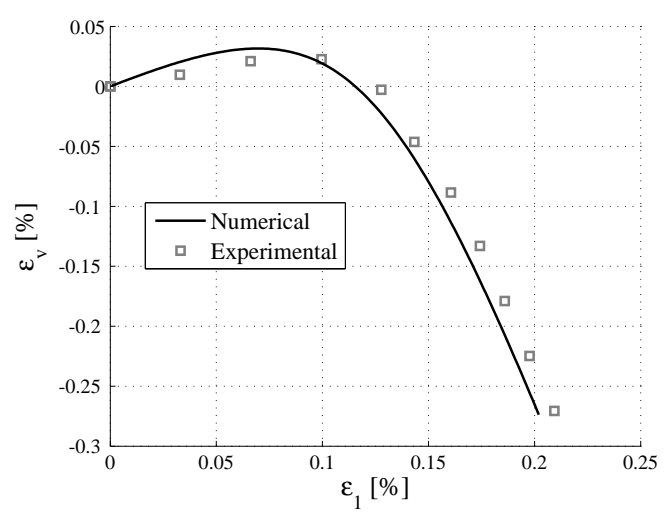

Fig. 10: Comparison of monotonic simple compression simulation and experimental results, volumetric $\epsilon_{v}$ vs. axial $\epsilon_{1}$ strain before peak, Lorano marble, experimental results from (Royer-Carfagni \& Salvatore, 2000)

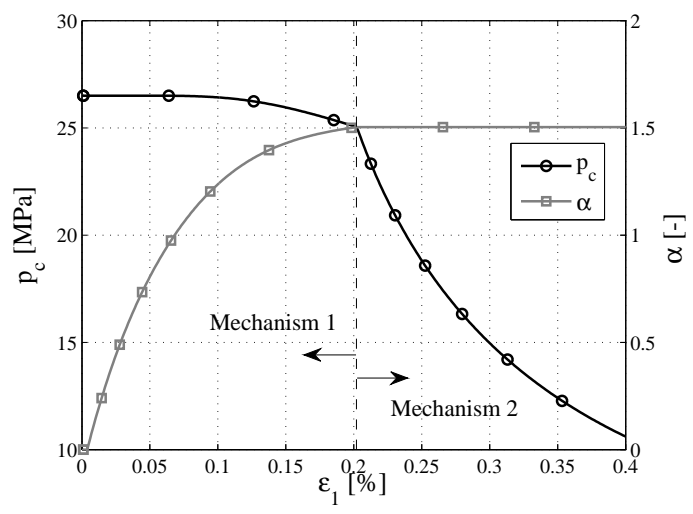

Fig. 11: Evolution of internal variables $\mathrm{p}_{c}$ and $\alpha$ during the simple compression test, Lorano marble 

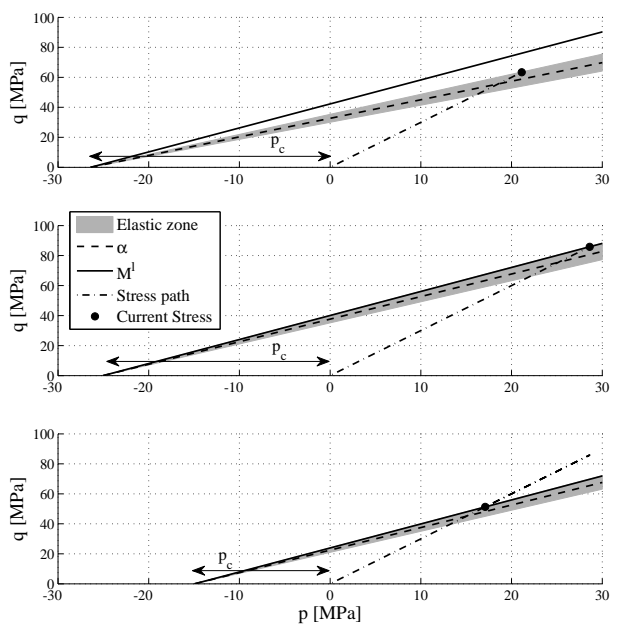

Fig. 12: Evolution of yield and limit surfaces during the simple compression test for three different vertical strain $\epsilon_{1}(0.1 \%$ top, $0.2 \%$ middle, $0.3 \%$ bottom), Lorano marble

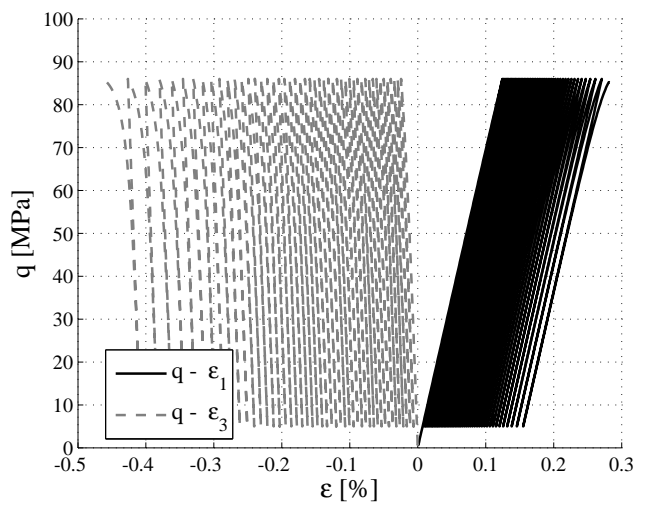

Fig. 13: Deviatoric stress q versus axial $\epsilon_{1}$ or lateral $\epsilon_{3}$ strain, cyclic simple compression test, Lorano marble 


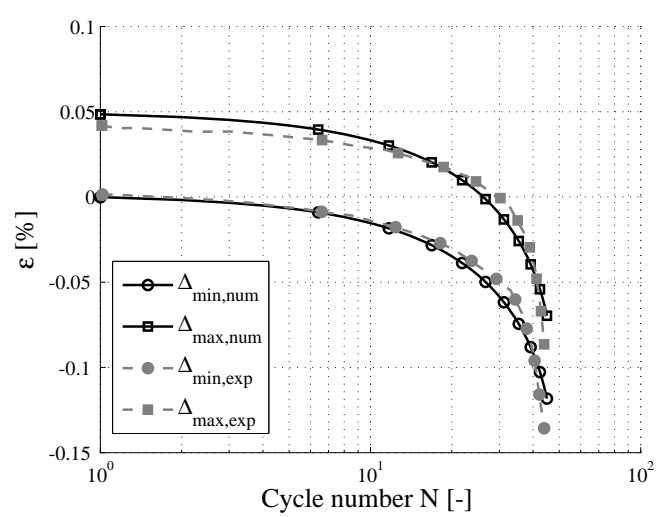

Fig. 14: Indicators of maximum $\Delta_{\max }$ and minimum $\Delta_{\min }$ volumetric strain with the number of cycles N, Lorano marble, (Royer-Carfagni \& Salvatore, 2000) for experimental results

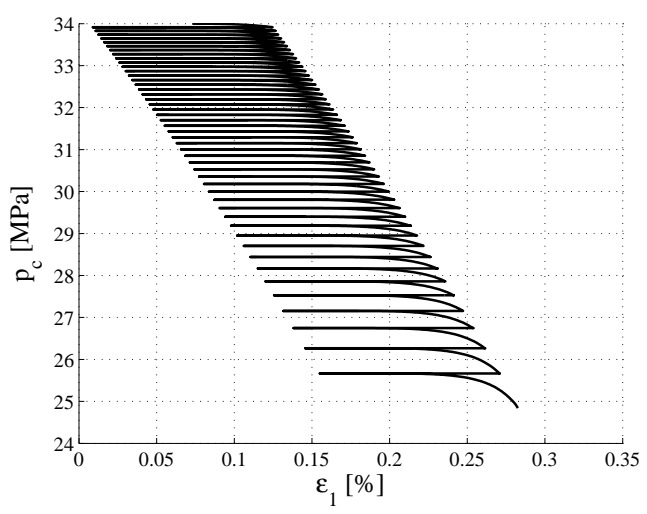

Fig. 15: Evolution of cohesion internal variable $\mathrm{p}_{c}$ with the number of cycles $\mathrm{N}$, Lorano marble 


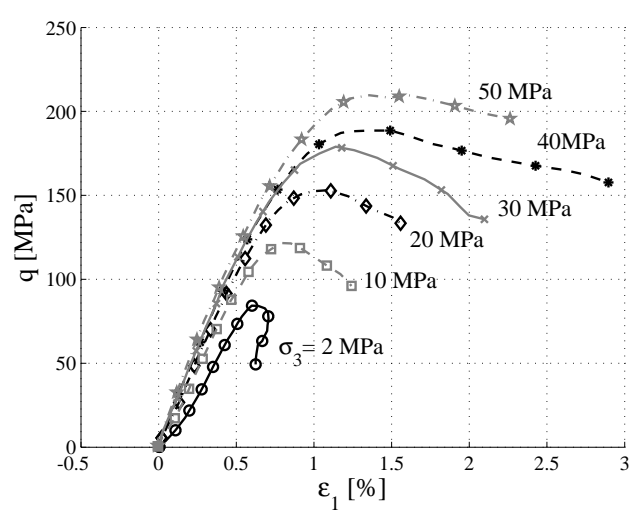

Fig. 16: Monotonic compression triaxial tests at six confining pressures, deviatoric stress q versus axial strain $\epsilon_{1}$, sandstone, (Liu \& He, 2012)

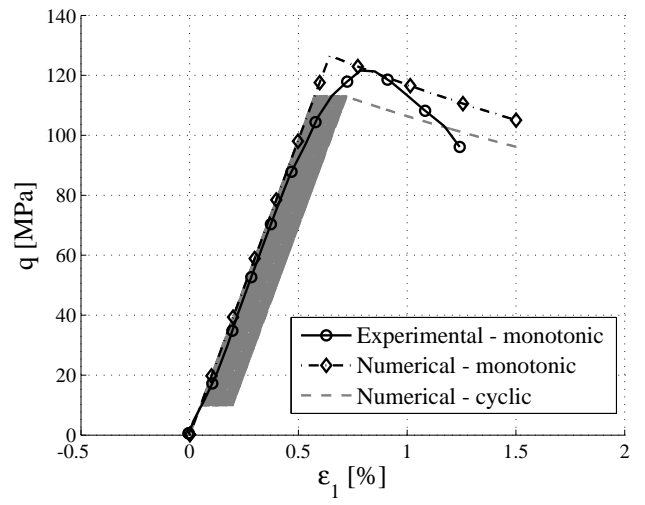

Fig. 17: Triaxial compression test (confining pressure $=10 \mathrm{MPa}$ ), deviatoric stress $\mathrm{q}$ versus axial strain $\epsilon_{1}$, sandstone, experimental results from (Liu \& He, 2012) 


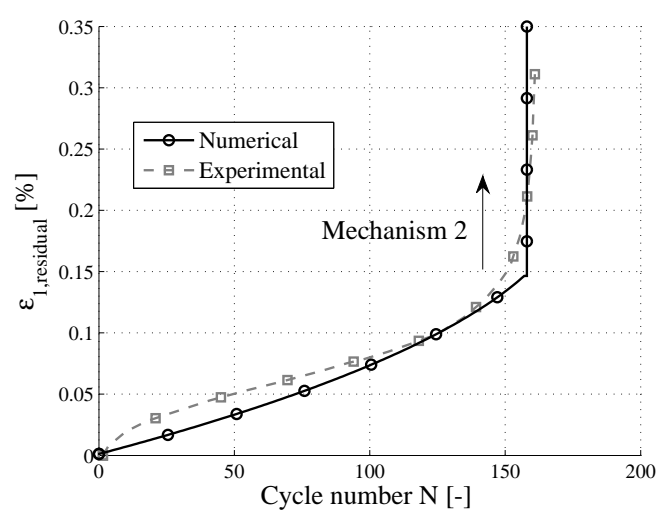

Fig. 18: Cyclic triaxial compression test, axial residual strain $\epsilon_{1}^{p}$ versus number of cycles $\mathrm{N}$, experimental results from (Liu \& He, 2012)

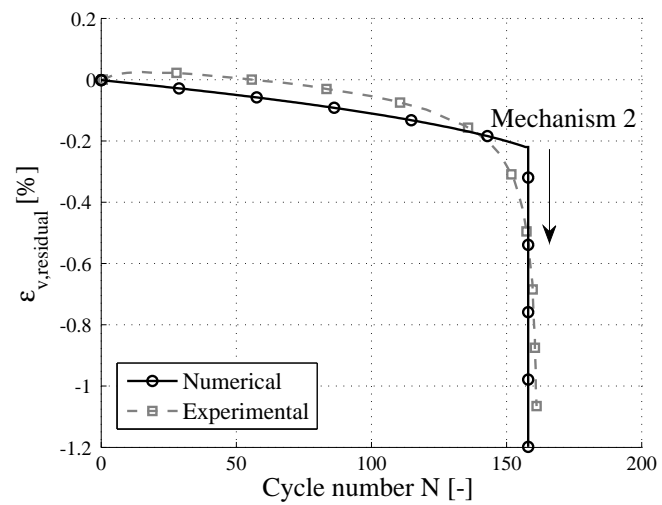

Fig. 19: Cyclic triaxial compression test, volumetric residual strain $\epsilon_{1}^{p}$ versus number of cycles N, experimental results from (Liu \& He, 2012) 


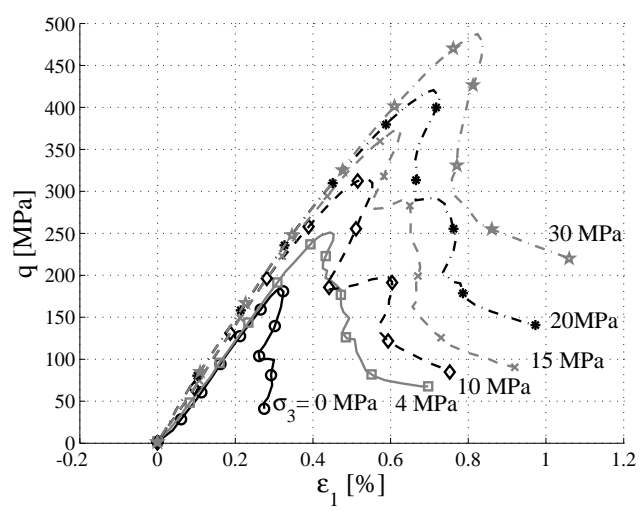

Fig. 20: Monotonic compression triaxial tests at six confining pressures, deviatoric stress q versus axial strain $\epsilon_{1}$, Lac du Bonnet granite, (Martin, 1997)

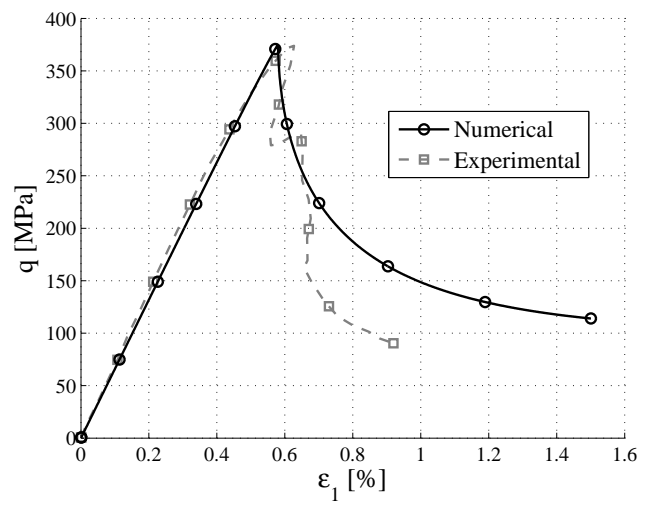

Fig. 21: Triaxial compression test (confining pressure $=15 \mathrm{MPa}$ ), deviatoric stress q versus axial strain $\epsilon_{1}$, Lac du Bonnet granite, experimental results from (Martin, 1997) 


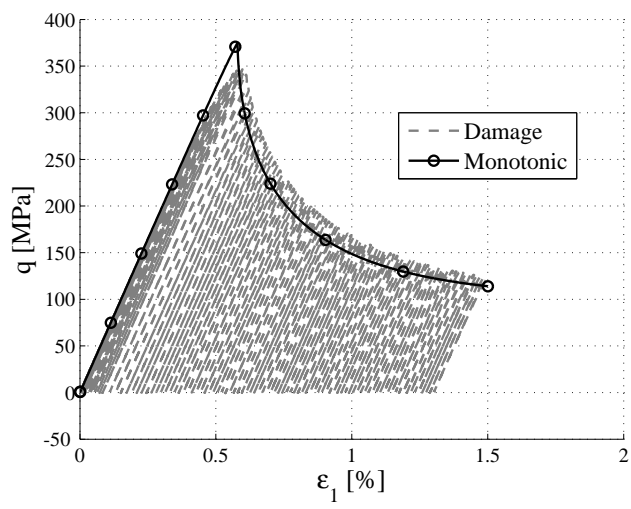

Fig. 22: Damage controlled test and monotonic tests, deviatoric stress q versus axial strain $\epsilon_{1}$

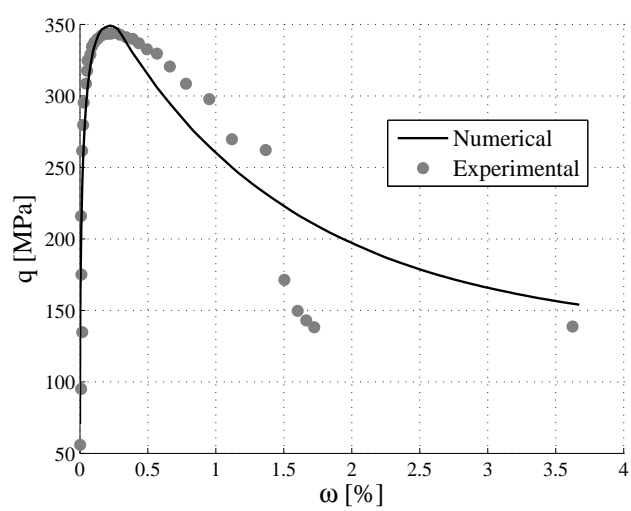

Fig. 23: Damage controlled test, deviatoric stress q versus damage $\omega$, experimental data from (Martin \& Chandler, 1994) 


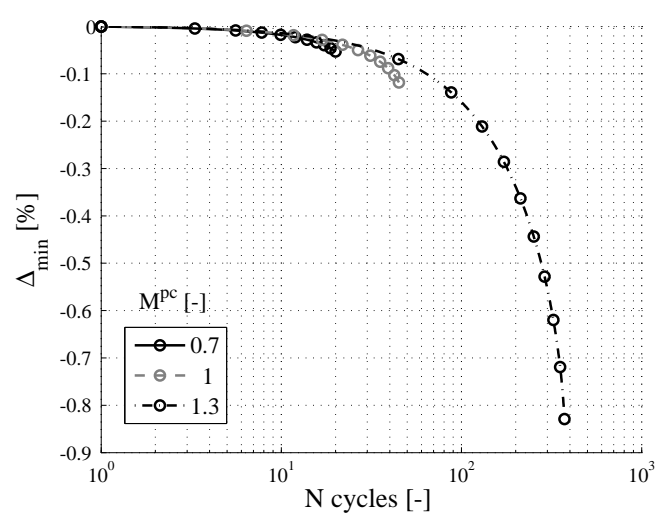

Fig. 24: Indicators of minimum $\Delta_{\min }$ volumetric strain with the number of cycles $\mathrm{N}$, Lorano marble, influence of $\mathbf{M}^{p c}$ parameter

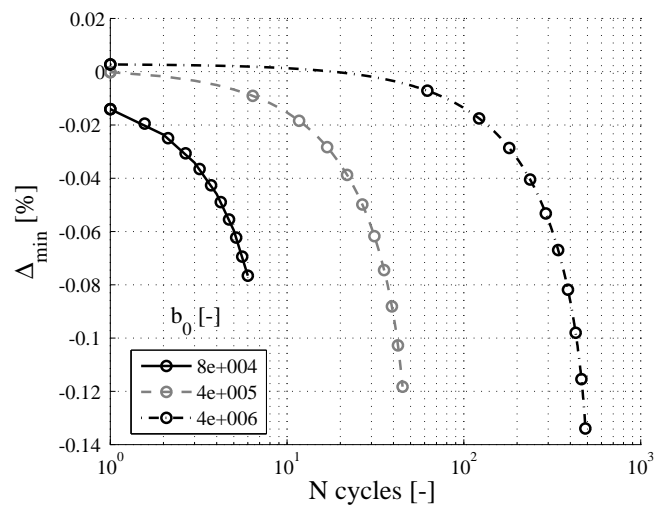

Fig. 25: Indicators of minimum $\Delta_{\min }$ volumetric strain with the number of cycles $\mathrm{N}$, Lorano marble, influence of $b_{0}$ parameter 


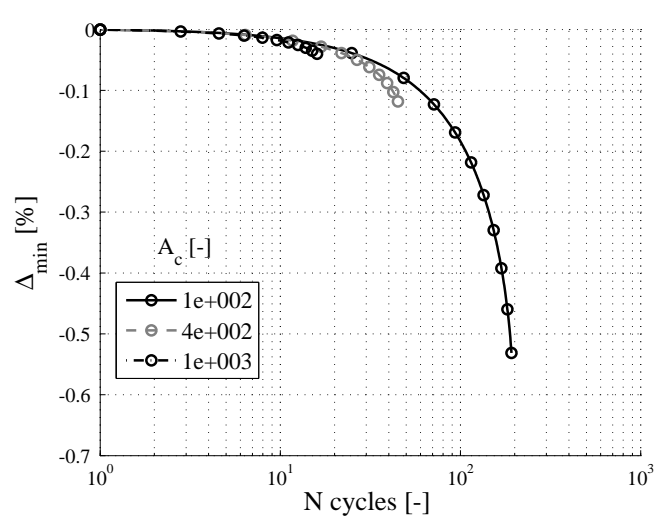

Fig. 26: Indicators of minimum $\Delta_{\min }$ volumetric strain with the number of cycles $\mathrm{N}$, Lorano marble, influence of $A_{c}$ parameter 


\begin{tabular}{|c|c|c|c|c|}
\hline & Function & Parameter & Experimental test & Recommended value \\
\hline $\begin{array}{l}\text { Young modulus } \\
\text { Poisson's ratio } \\
\text { Elastic opening }\end{array}$ & Elasticity & $\begin{array}{c}\mathrm{E} \\
\nu \\
\mathrm{M}^{y}\end{array}$ & $\begin{array}{l}\text { Uniaxial compression } \\
\text { Triaxial compression }\end{array}$ & $0.05-0.1$ \\
\hline $\begin{array}{c}\text { Failure slope } \\
\mathrm{p}_{c} \text { degradation } \\
\text { Residual } \mathrm{p}_{c} \\
\text { Fatigue limit slope }\end{array}$ & Failure & $\begin{array}{c}\mathrm{M}^{l},\left(\delta_{l}\right) \\
A_{c 1} / A_{c 2} \\
\mathrm{p}_{\text {res }} \\
\mathrm{M}^{p c}\end{array}$ & $\begin{array}{l}\text { Triaxial compression /traction } \\
\text { Uniaxial compression } \\
\text { Uniaxial/Triaxial compression } \\
\text { Cyclic triaxial }\end{array}$ & $\begin{aligned} & 0-5 \\
\sim & 0.7 \mathrm{M}^{p c}\end{aligned}$ \\
\hline $\begin{array}{c}\text { Bounding slope } \\
\mathrm{p}_{c} \text { evolution } \\
\alpha \text { evolution } \\
\text { Stiffness } \\
\end{array}$ & Hardening & $\begin{array}{l}\mathrm{M}^{b} \\
n_{p c} \\
n_{\alpha} \\
b_{0}\end{array}$ & $\begin{array}{c}\text { Triaxial compression } \\
\text { Triaxial compression } \\
\text { Triaxial compression } \\
\text { Cyclic triaxial }\end{array}$ & $\begin{array}{l}0 \\
1\end{array}$ \\
\hline Dilatancy & Volumetric behaviour & $A_{d}$ & Uniaxial compression & \\
\hline $\begin{array}{l}\text { Kinematic } \\
\text { Cohesion }\end{array}$ & Internal variables & $\begin{array}{c}\alpha \\
\mathrm{p}_{c}\end{array}$ & $\begin{array}{c}\text { / } \\
\text { Triaxial compression }\end{array}$ & 0 \\
\hline
\end{tabular}

Table 1: Name and function of parameters and internal variables, experimental tests required for their calibration (monotonic test if nit specified)

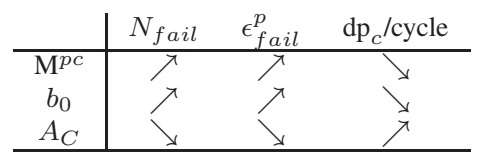

Table 2: Influence of increasing one of the three main parameters on the number of cycles to failure $\left(N_{f a i l}\right)$, the plastic strain at failure $\left(\epsilon_{f a i l}^{p}\right)$ and the degradation rate/cycle $\left(\mathrm{dp}_{c} /\right.$ cycle $)$

\begin{tabular}{|c|c|c|c|c|c|c|c|c|c|c|c|c|c|c|c|c|}
\hline $\begin{array}{c}\text { Symbol } \\
\text { Unit }\end{array}$ & $\begin{array}{c}\mathbf{M}^{y} \\
{[-]}\end{array}$ & $\begin{array}{c}\mathrm{E} \\
{[\mathrm{GPa}]}\end{array}$ & $\begin{array}{c}\nu \\
{[-]}\end{array}$ & $\begin{array}{c}\mathrm{M}^{l} \\
{[-]}\end{array}$ & $\begin{array}{c}\mathrm{p}_{\text {res }} \\
{[\mathrm{MPa}]}\end{array}$ & $\begin{array}{l}\delta_{l} \\
{[-]}\end{array}$ & $\begin{array}{c}\mathbf{M}^{p c} \\
{[-]}\end{array}$ & $\begin{array}{c}A_{c 1} \\
{[-]}\end{array}$ & $\begin{array}{c}A_{c 2} \\
{[-]}\end{array}$ & $\begin{array}{c}n_{p c} \\
{[-]}\end{array}$ & $\begin{array}{c}\mathbf{M}^{b} \\
{[-]}\end{array}$ & $\begin{array}{l}n_{\alpha} \\
{[-]}\end{array}$ & $\begin{array}{l}b_{0} \\
{[-]}\end{array}$ & $\begin{array}{l}A_{d} \\
{[-]}\end{array}$ & $\begin{array}{l}\alpha_{0} \\
{[-]}\end{array}$ & $\begin{array}{c}\mathrm{p}_{c 0} \\
{[\mathrm{MPa}]}\end{array}$ \\
\hline Lorano & 0.1 & 70.0 & 0.16 & 1.60 & 5 & 1 & 1.0 & 110 & 500 & 0 & 1.70 & 1 & $6 \cdot 10^{4}$ & -1.8 & 0 & 26.5 \\
\hline Sandstone & 0.1 & 19.7 & 0.125 & 1.24 & 5 & 1 & 0.8 & 270 & 50 & 0 & 1.30 & 1 & $3 \cdot 10^{6}$ & -1.0 & 0 & 50.0 \\
\hline Granite & 0.1 & 66 & 0.27 & 2.07 & 0 & 1 & 1.4 & 350 & 350 & 0 & 2.17 & 1 & $1.2 \cdot 10^{6}$ & -1.5 & 0 & 42 \\
\hline
\end{tabular}

Table 3: Calibrated parameters for three different materials: Lorano marble (RoyerCarfagni \& Salvatore, 2000), sandstone (Liu \& He, 2012) and granite (Martin \& Chandler, 1994) 